Original title / titulo original: Los trabajos de las Expediciones Peruanas de Yale en la Llaqta de Machupicchu

\title{
Author(s)/ autor(es):
}

José Bastante Director del Programa de Investigaciones Arqueológicas e Interdisciplinarias en el Santuario Histórico de Machupicchu, Dirección Desconcentrada de Cultura Cusco, Ministerio de Cultura.

Published originally as/ Publicado originalmente en:

URL: http://estudioslatinoamericanos.pl/index.php/estudios/article/view/ES 3637 art2

DOI: https://doi.org/10.36447/Estudios2017.v36-37.art2

Estudios Latinoamericanos is a journal published by Polish Society for Latin American Studies (Polskie Towarzystwo Studiów Latynoamerykanistycznych).

Polish Society for Latin American Studies is scholarly organization established to facilitate research on Latin America and to encourage and promote scientific and cultural cooperation between Poland and Latin America.

Estudios Latinoamericanos, revista publicada por la Sociedad Polaca de Estudios Latinoamericanos (Polskie Towarzystwo Studiów Latynoamerykanistycznych).

Sociedad Polaca de Estudios Latinoamericanos es una asociación científica fundada con el fin de desarrollar investigaciones científicas sobre América Latina y participar

en la cooperación científica y cultural entre las sociedades de Polonia y América 


\title{
Los trabajos de las Expediciones Peruanas de Yale en la Llaqta de Machupicchu
}

\author{
José Bastante
}

\section{Resumen}

Se discuten los eventos e implicancias de las Expediciones Peruanas de Yale (EPY) en base al procesamiento de la información de las publicaciones, documentos, diarios de campo, registros gráficos e informes de las labores efectuadas durante 1911 y 1912 en la Llaqta de Machupicchu. Asimismo, se presenta el primer plano de las excavaciones ejecutadas durante 1912, el mismo que ha sido elaborado en función al diario de campo del ingeniero Ellwood Erdis.

Palabras clave: Machupicchu, Hiram Bingham, descubrimiento científico, Universidad de Yale, Ellwood Erdis, excavaciones.

Abstract

THE WORK OF THE YALE PERUVIAN EXPEDITIONS IN THE LLAQTA OF MACHUPICCHU

The events and implications of the Yale Peruvian Expeditions (YPE) are discussed through the information contained in publications, documents, field diaries, graphic records and reports of the works executed during 1911 and 1912 in the Llaqta of Machupicchu. Also, the first plan of the excavations that took place during 1912 is presented, this plan has been elaborated based on the field diary of engineer Ellwood Erdis.

Keywords: Machupicchu, Hiram Bingham, scientific discovery, Yale University, Ellwood Erdis, excavations.

José Bastante - Director del Programa de Investigaciones Arqueológicas e Interdisciplinarias en el Santuario Histórico de Machupicchu, Dirección Desconcentrada de Cultura Cusco, Ministerio de Cultura. Correo-e: jose.bastante@gmail.com 
Para la arqueología resulta un elemento imprescindible contar con los antecedentes de excavaciones ejecutadas en el sitio donde se pretenden realizar investigaciones. En algunos casos el acceso a informes, documentos, diarios y libretas de campo de determinadas intervenciones es limitado. Esta es la situación de las investigaciones arqueológicas ejecutadas en la Llaqta de Machupicchu previas al año 2013, las que no han contado con la información respecto a las excavaciones ejecutadas por la segunda de las Expediciones Peruanas de Yale (EPY) durante el año 1912.

\section{Las primeras labores de documentación y el mito del descubrimiento}

El 24 de julio de 1911, el profesor y explorador estadounidense Hiram Bingham III al mando de la primera EPY descubrió científicamente la Llaqta de Machupicchu. Al sexto día después de haber salido de la ciudad de Cusco arribó a Mandorpampa (Bingham 1913: 403). Guiado por Melchor Arteaga ${ }^{1}$ y en compañía del Sargento GC Fabián Carrasco, ascendió por un camino que se traza de forma similar y en algunos casos coincide con el actual camino que emplean los turistas que ascienden a la Llaqta desde el Puente Ruinas.

Bingham fue el primero en realizar un registro fotográfico del sitio (Fig. 1 y 2) y de levantar un croquis general y otro de la Plaza de los Templos (Fig. 3 y 4). Sin embargo, en esta oportunidad su visita fue relativamente corta ya que no permaneció más de tres horas en el lugar. Lo que Bingham buscaba eran las «ciudades» de Vitcos y Vilcabamba la vieja, y la ubicación de la Llaqta de Machupicchu no correspondía con las referencias que brindaban al respecto los documentos históricos que disponía, principalmente las crónicas del padre Antonio de la Calancha (1638), Baltasar de Ocampo (1610) y la Relación de Diego Rodríguez de Figueroa (1565) (Bingham 1912, 1922, 1930, 1948).

Cabe notar que Rowe acusó a Bingham de omitir la mención a Picchu de la «relación» de Figueroa, ${ }^{2}$ debido a que hubiera desbaratado totalmente su hipótesis de que Machupicchu era «Vilcabamba la vieja» (Rowe 1990: 140). Sin embargo, resulta evidente que dicho autor no tuvo acceso a la obra más importante de las investigaciones de las EPY, ya que si bien Bingham indica que no existe ninguna mención directa respecto a la Llaqta de Machupicchu, también señala que la alusión a «Picchu» en el texto de Figueroa podría ser una referencia a ésta (Bingham 1930: 1).

$\mathrm{Al}$ margen de que en la actualidad todas las hipótesis de Bingham respecto a la Llaqta de Machupicchu han sido descartadas, el explorador notó de inmediato la importancia del sitio y envió a dos de sus asistentes, los señores Paul Lanius y Herman Tucker con el fin de documentar con mayor precisión el monumento.

Lanius y Tucker llegaron a la zona en septiembre de 1911 pero no pudieron ascender a la Llaqta por el mismo camino que empleó Bingham debido a que el río Vilcanota había aumentado considerablemente su caudal y solo quedaba en pie un 


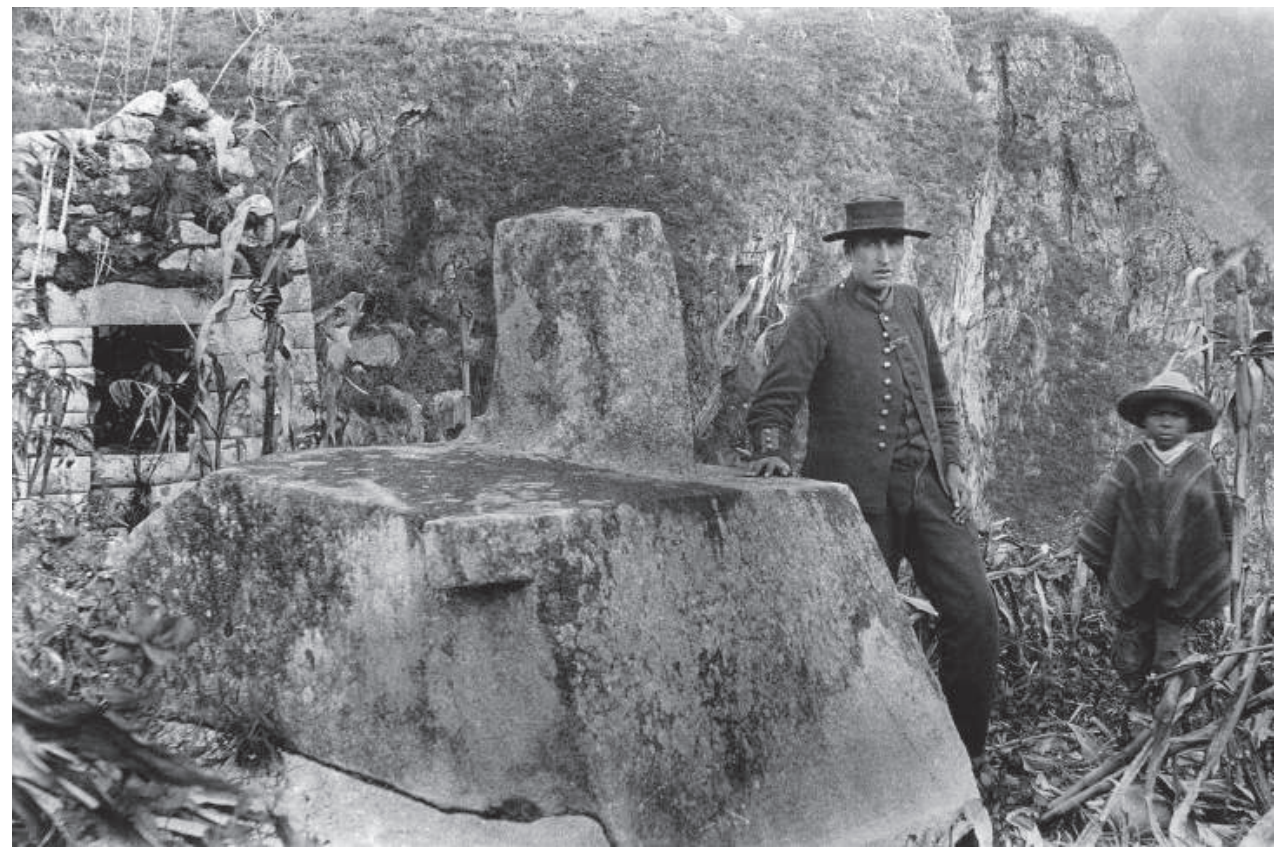

Figura 1. El sargento Fabián Carrasco y el niño Richarte en una de las primeras fotografías tomadas por Bingham el 24 de julio de 1911 - Cortesía National Geographic Society. Nótese el hastial del recinto, el elemento lítico de la base de la ventana y el cultivo de maíz en la plataforma.

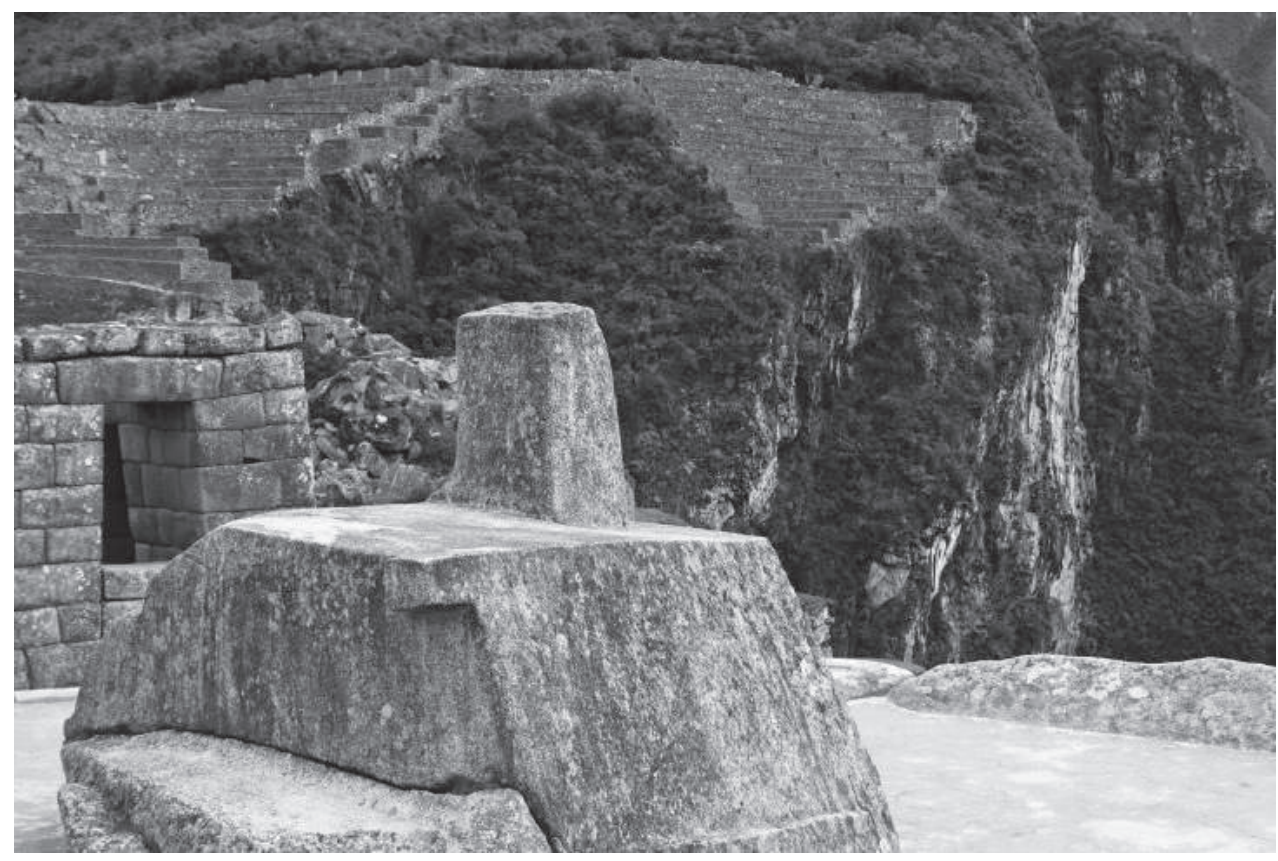

Figura 2. Fotografía tomada en 2014 - José Bastante. Nótese el hastial del recinto reducido y el elemento lítico faltante en la base de la ventana. 


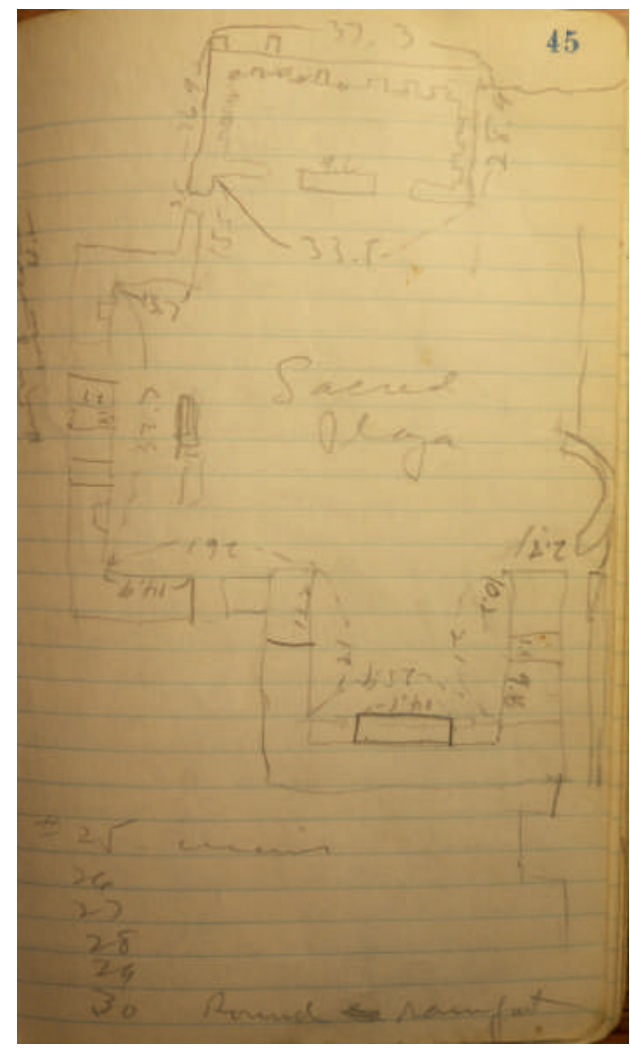

Figura 3. Croquis de la Plaza de los Templos. Tomado de Bingham (1911a:45).

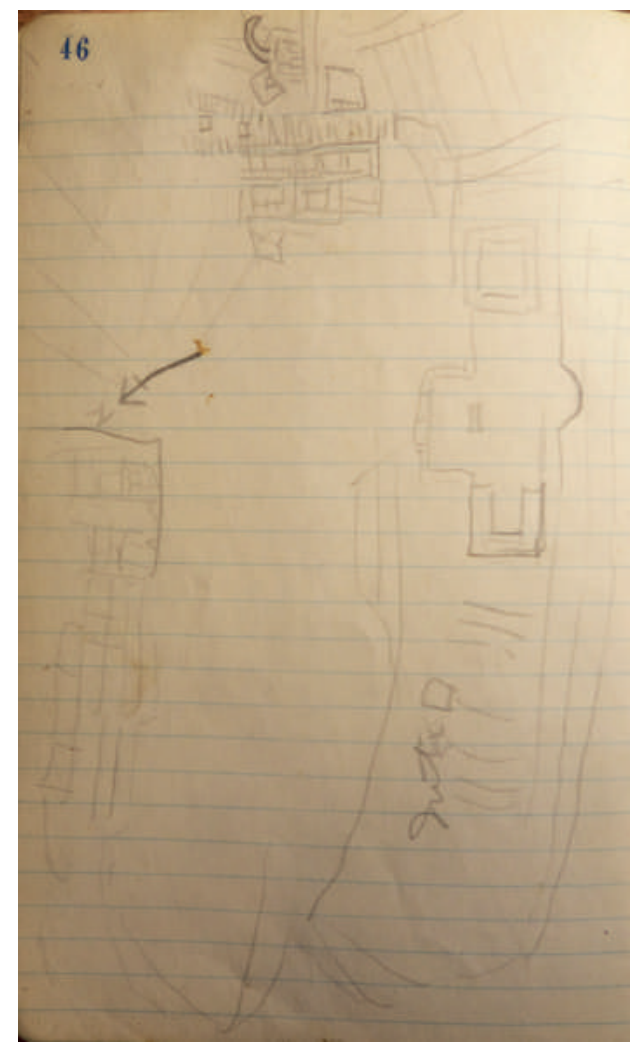

Figura 4. Croquis de la Llaqta de Machupicchu. Tomado de Bingham (1911a:46).

tronco del puente de Arteaga que había empleado Bingham unas semanas atrás (1930: 3). Un reconocimiento sistemático de los elementos líticos en el río Vilcanota entre los kilómetros 110 y 116 de la vía férrea y su comparación con las fotografías de la EPY de 1911 nos ha permitido identificar la ubicación exacta del puente a 30 metros río abajo del actual Puente Ruinas (Fig. 5 y 6) y en base a los dibujos, descripciones y fotografías de Bingham (1930: 4-7) se ha evidenciado que es el mismo lugar donde el ingeniero Heald construyó en 1912 el puente de la EPY (Fig. 7 y 8).

Debido a lo expuesto, Lanius y Tucker tuvieron que ascender al monumento por otro camino que partía cerca del puente San Miguel, el cual era usado frecuentemente por Álvarez y Richarte (Bingham 1930: 3), campesinos que cultivaban algunos andenes de la Llaqta. Tanto Eaton (1916) como Bingham (1930: 3-4) ubican este camino en sus planos además de mencionar que era peligroso y más largo para acceder a la Llaqta (Eaton 1916; Bingham 1930; Cosio 1912 a, b) (Fig. 9 y 10). Actualmente, solo segmentos de este camino son transitables pero se tienen identificados otros ocho caminos que conectan a la Llaqta con los demás monumentos arqueológicos de la zona (Bastante 2016a: 274). 


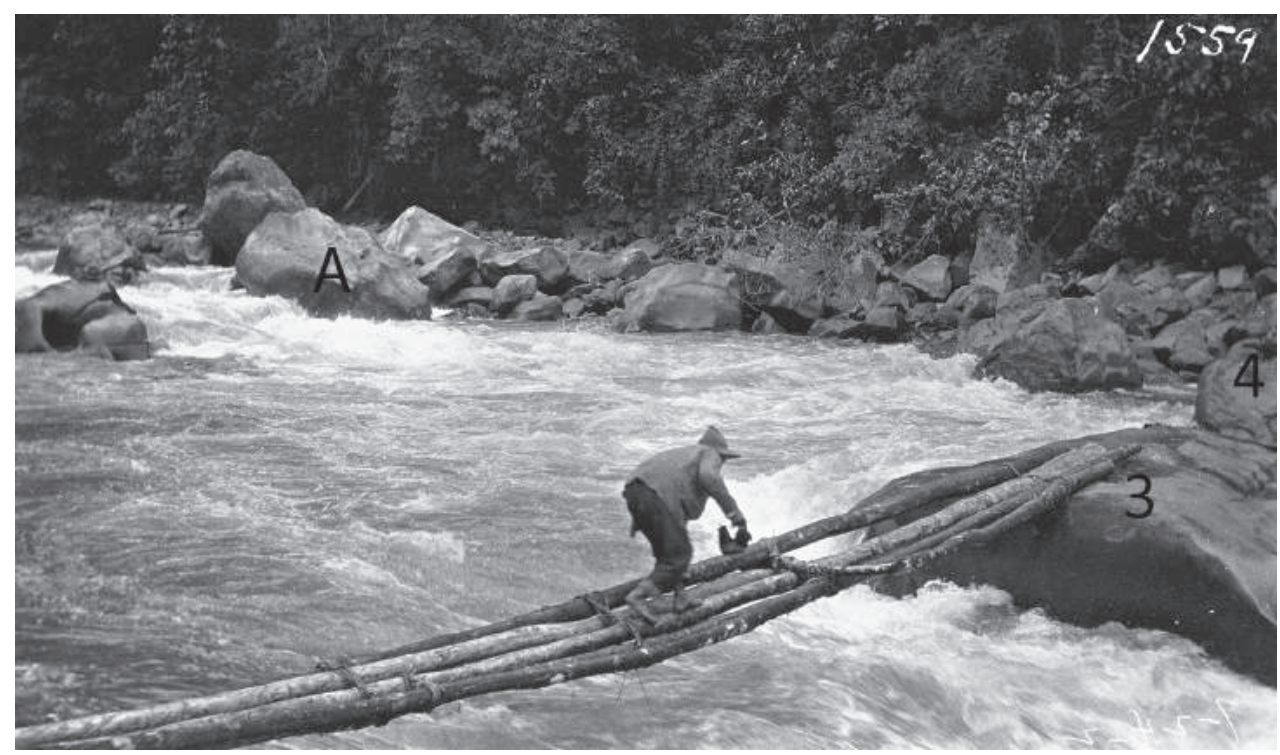

Figura 5. Puente de Melchor Arteaga. Fotografía Hiram Bingham (1911) - Cortesía National Goegraphic Society.

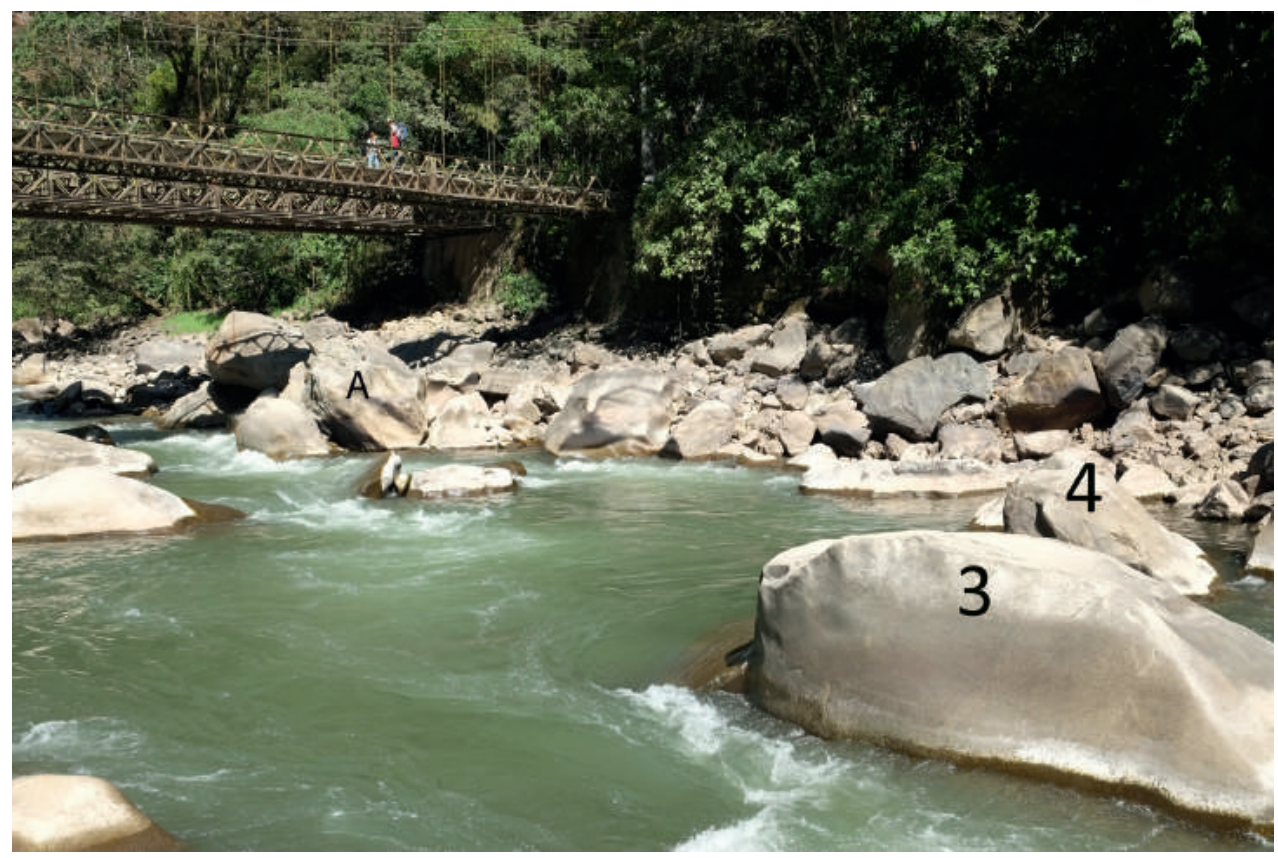

Figura 6. Ubicación del puente de Arteaga en relación al Puente Ruinas. Fotografía José Bastante. 


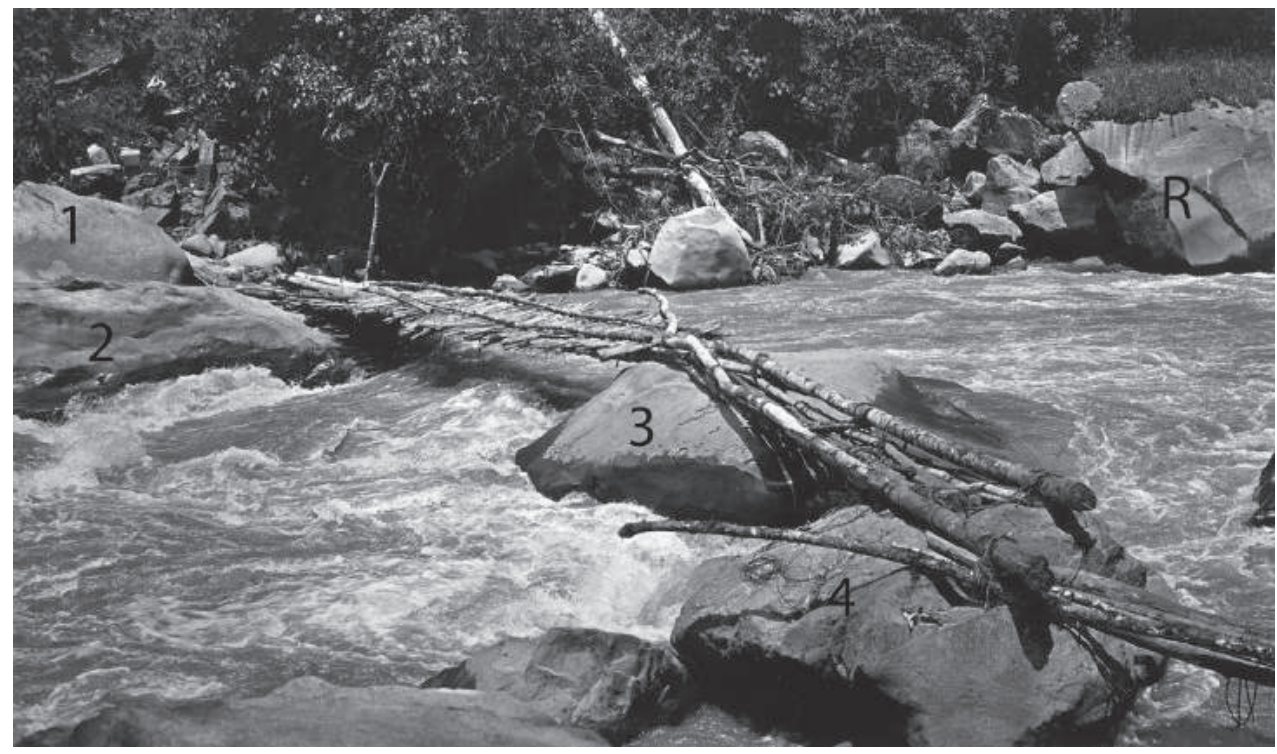

Figura 7. Puente de Heald. Fotografía Hiram Bingham (1912) - Cortesía National Geographic Society.

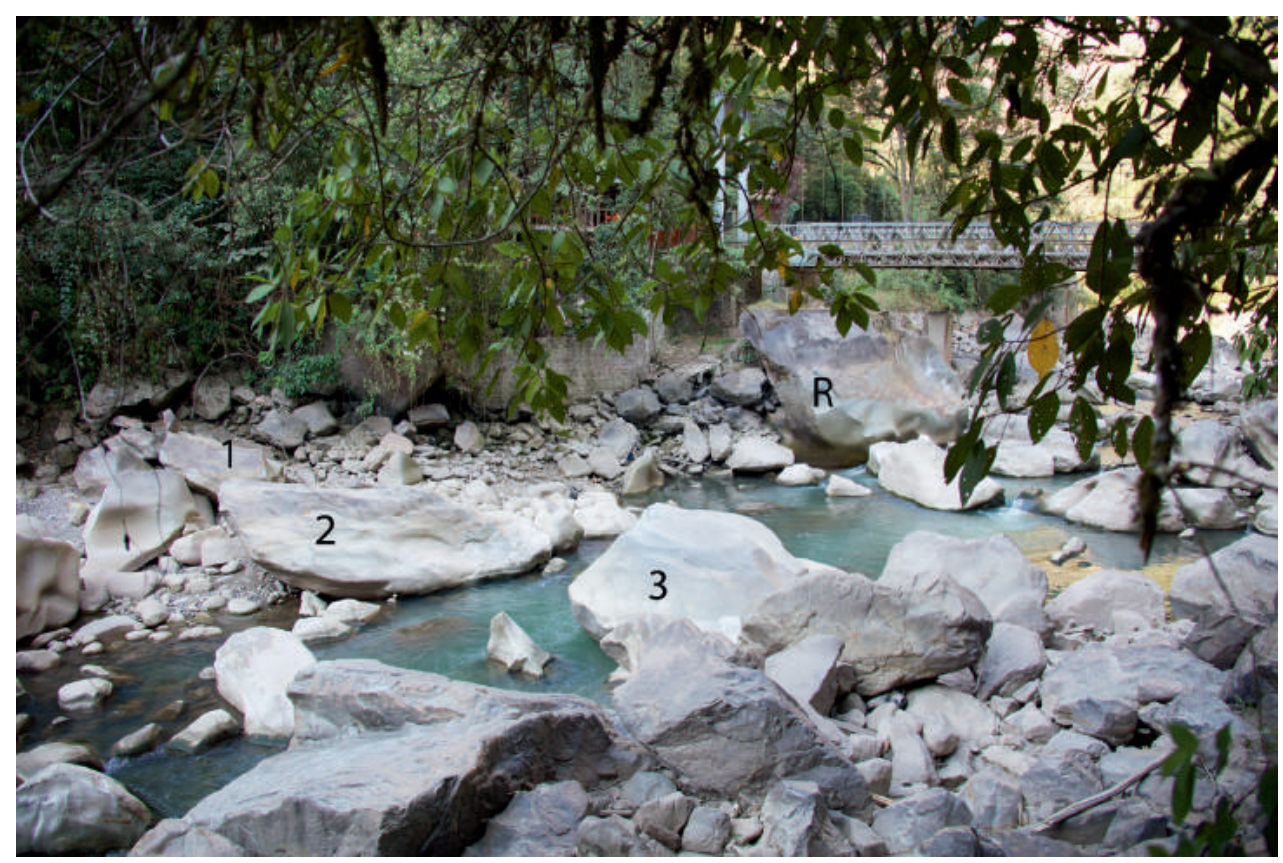

Figura 8. El puente de Heald se ubicó en el mismo lugar donde estuvo el puente de Arteaga. Fotografía José Bastante. 


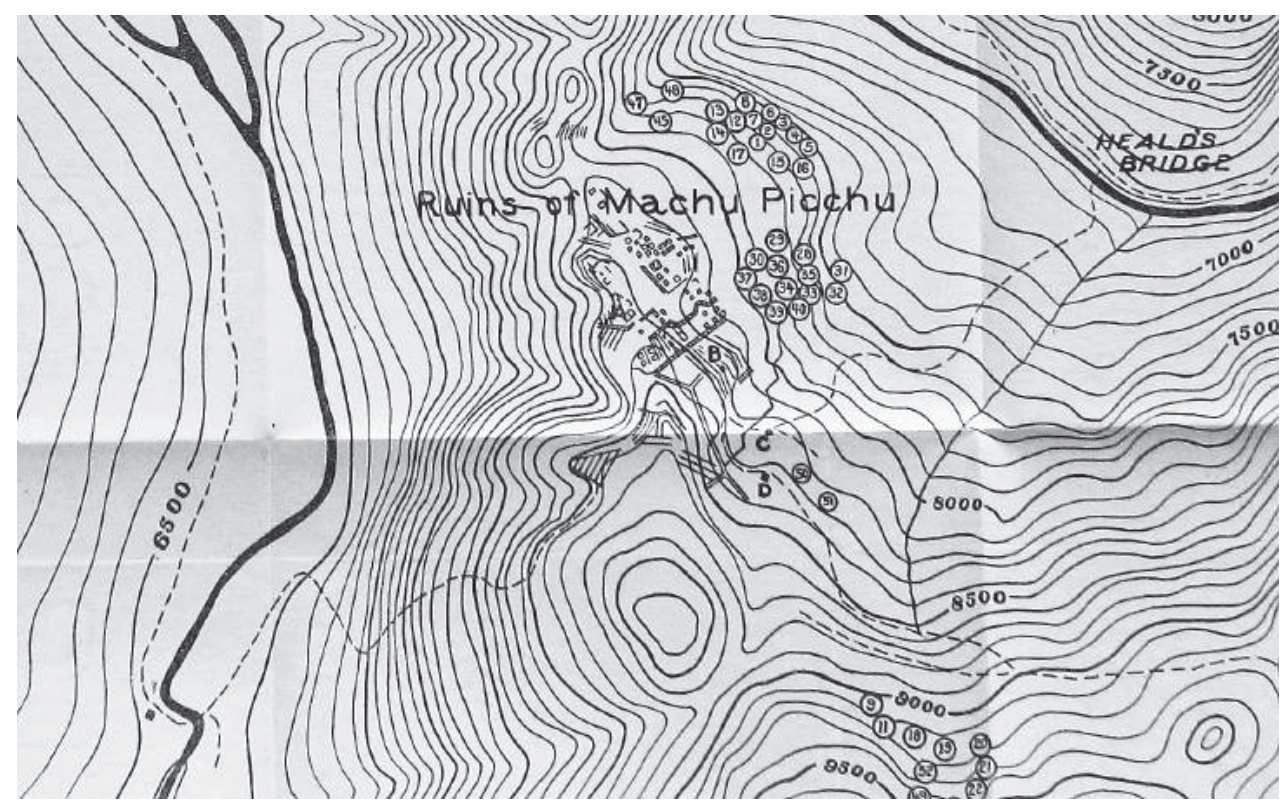

Figura 9. Porción del plano de Eaton (1916) donde se presentan dos caminos de acceso a la Llaqta de Machupicchu empleados por la EPY de 1912.

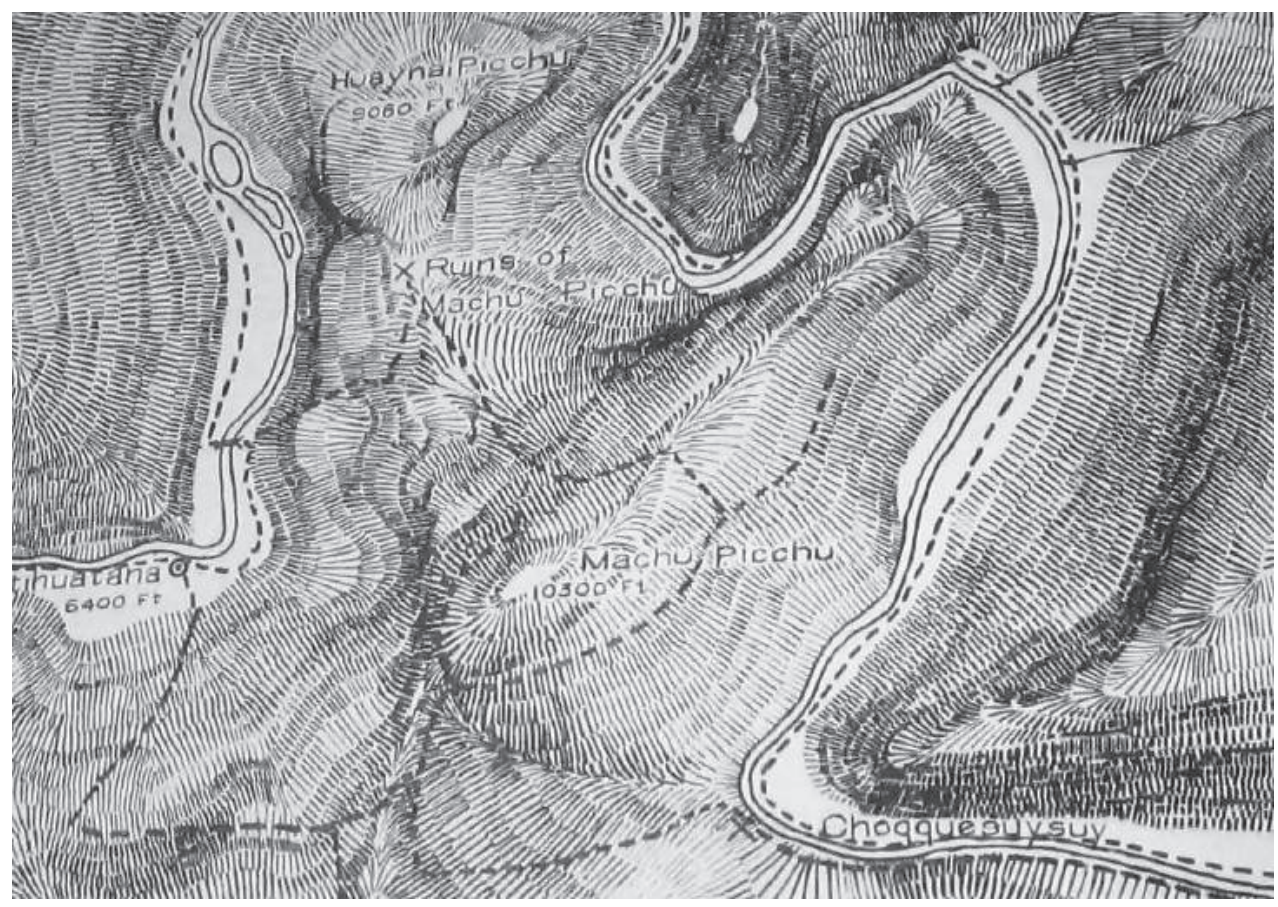

Figura 10. Porción del plano de Bingham (1930) donde se presentan los caminos de acceso a la Llaqta de Machupicchu definidos por las EPY. 
Lanius se contactó con Ángel Lizárraga, ${ }^{3}$ quien se encargó de contratar al personal de la zona (Intiwatana y San Miguel) para realizar la primera limpieza general de la Llaqta de Machupicchu. Lizárraga recibió dos soles por día, mientras que cada uno de los cinco asistentes quechua hablantes recibieron un sol diario por su trabajo. Al estar a merced de Lizárraga, debido a que era el único que se podía comunicar con los asistentes, Lanius tuvo que aceptar sus condiciones y cubrir los gastos de coca, aguardiente y del supuesto alquiler de los machetes (1911: 33, 35-37).

Las labores se iniciaron el 9 de septiembre de 1911. Durante dos semanas se realizaron quemas, corte de vegetación, limpieza, así como la toma de fotografías (Fig. 11 y 12), mediciones de algunos recintos, descripciones, dibujos y un plano que incluía las partes mejor conservadas del sitio. Algunos días el trabajo se prolongó hasta por doce horas, con pausas para el descanso y debido a las inclemencias del clima. Ángel Lizárraga continuó apoyando a la EPY el año siguiente (Bingham 1912).

La siguiente visita documentada fue la del profesor José Gabriel Cosio, quien arribó a la Llaqta de Machupicchu el 19 de enero de 1912 en compañía de Enrique y Fernando Palma, los hermanos Luis, José María y Justo A. Ochoa (de la hacienda Collpani), y tres indígenas no identificados (Cosio 1912a: 16-18). En esta oportunidad, Agustín Lizárraga ${ }^{4}$ fungió como el guía de la expedición (Cosio 1912a: 13). Cosio refiere la existencia de excavaciones clandestinas en numerosos lugares de la Llaqta (1912b: 20), algunas de las cuales fueron probablemente realizadas por

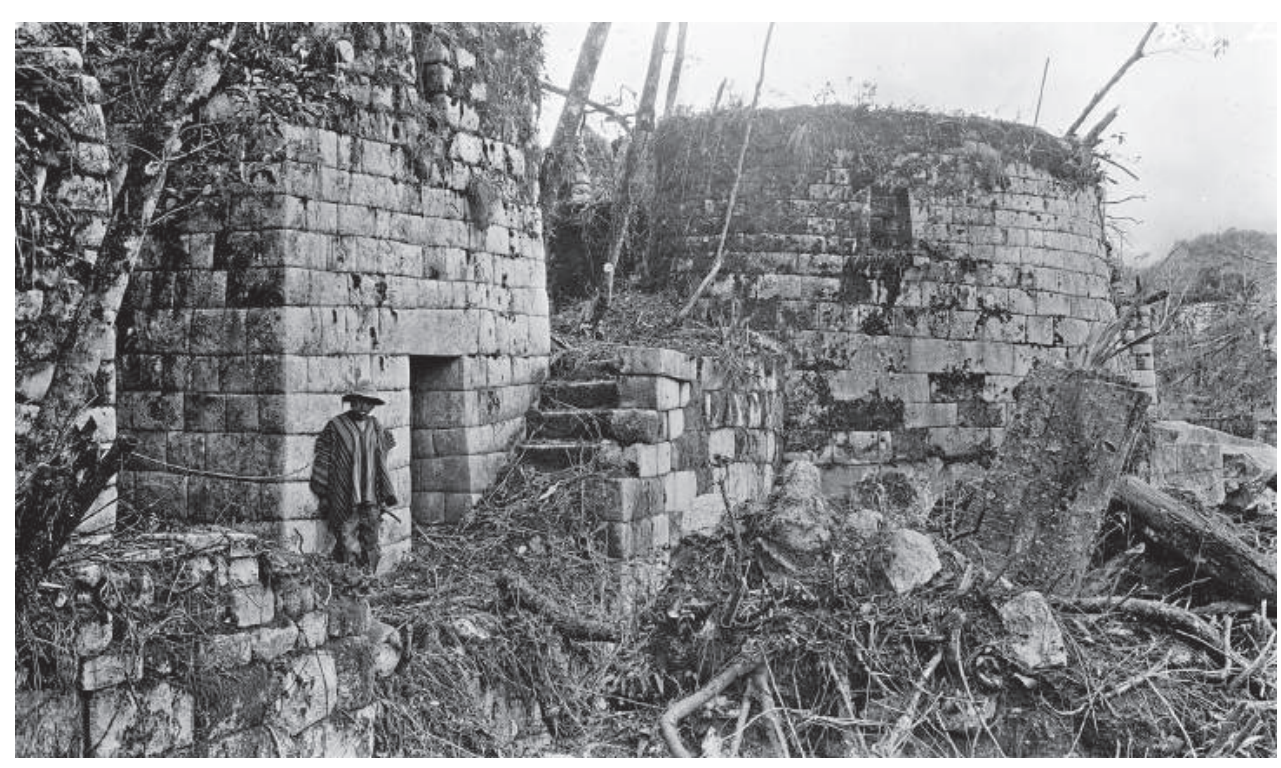

Figura 11. Fotografía tomada por Tucker durante la limpieza del sitio en setiembre de 1911 - Cortesía National Geographic Society. 


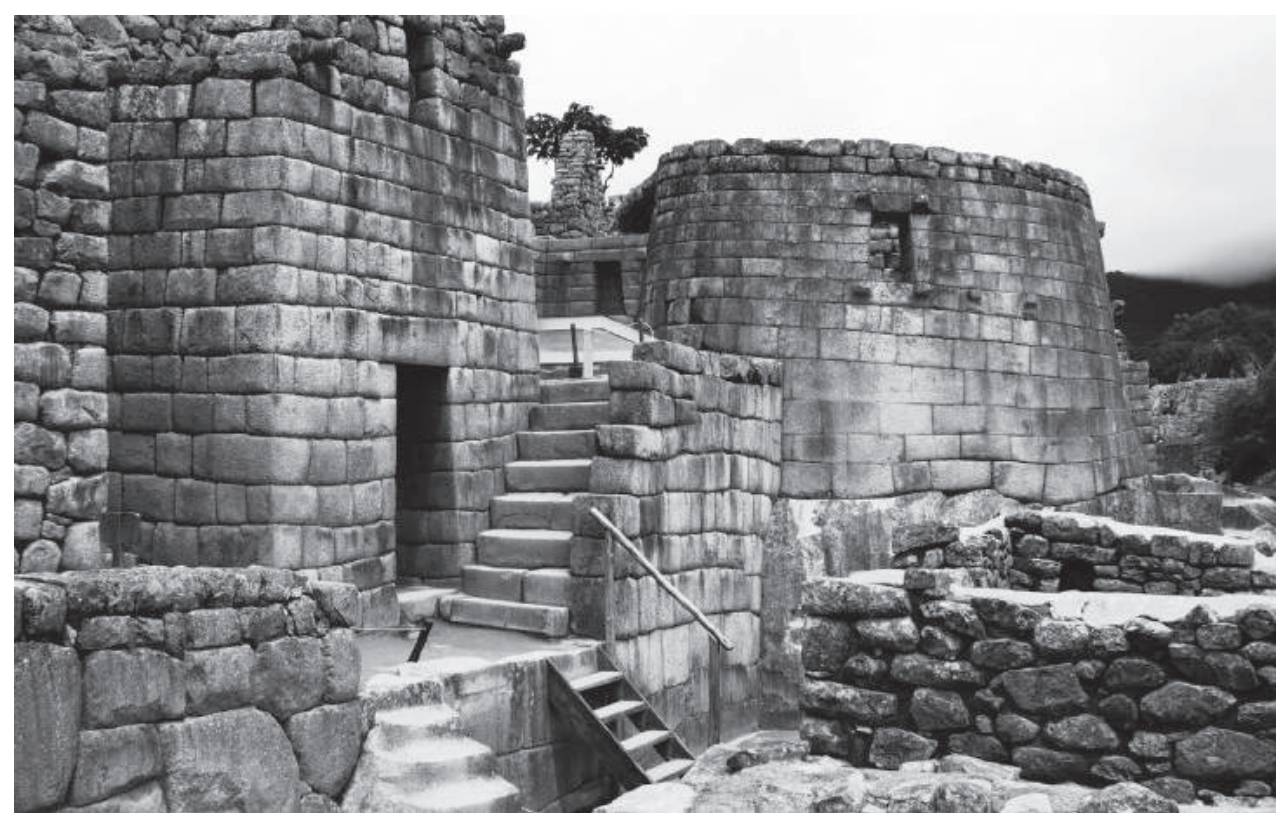

Figura 12. Fotografía que evidencia el excelente estado de conservación de los templos. Fotografía: José Bastante (2014).

los hermanos Lizárraga en sectores a los que no habían podido acceder con anterioridad a la masiva limpieza del sitio en 1911. Agustín Lizárraga era considerado en la zona, de acuerdo a la información proporcionada por Arteaga a Bingham, como el descubridor de la Llaqta de Machupicchu (Bingham 1911a: 44, 48, 1911b: 33).

Resulta interesante notar que durante su primera visita en 1911, Bingham encontró un grafiti de Agustín Lizárraga (1922: 324), el mismo que fue confirmado por Cosio en enero de 1912 (1913: 24). Si bien estas referencias indican sin mayor precisión que la inscripción de carbón estaba en uno de los templos, no fue hasta hace unos años que Fernando Astete (comunicación personal 2013) reparó una fotografía del Templo de las Tres Ventanas tomada por Bingham durante su primera visita, donde en la ventana central del templo de las Tres Ventanas figura la inscripción que reza «Lizárraga 1902» (Fig. 13). Dicha fotografía fue divulgada en un artículo de Bingham de abril de 1912 en la National Geographic Magazine e incluso anteriormente, en una publicación de Clements Markham en la edición de diciembre de 1911 de The Geographical Journal.

Lo que resulta evidente es que Agustín Lizárraga fue el primero de los buscadores de tesoros que dejó una inscripción en Llaqta de Machupicchu durante su visita inicial en 1902. De acuerdo con Cosio (1912a: 20, 21; 1913: 24), en dicha ocasión Lizárraga estuvo acompañado por Enrique Palma y Gavino Sánchez. Sin embargo, estos personajes no fueron los primeros en buscar tesoros en la Llaqta (Cosio 1912a, 1913). 


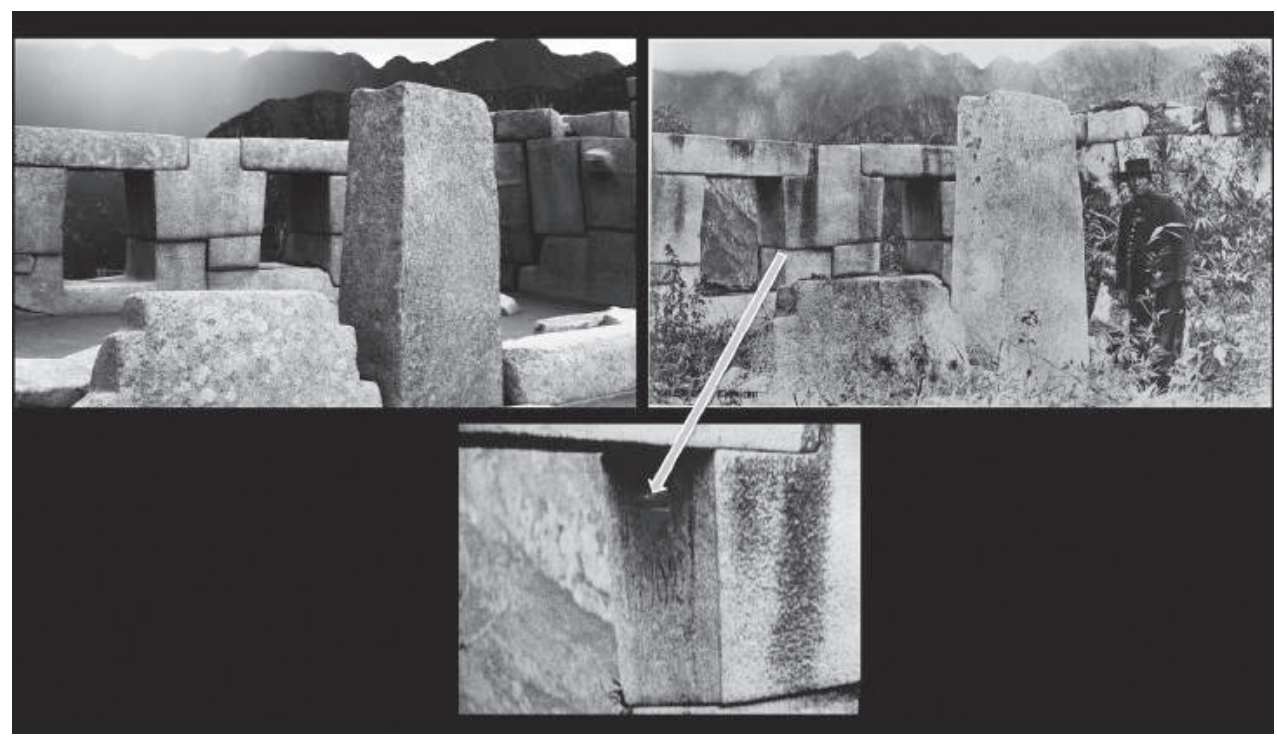

Figura 13. Inscripción en carbón de Agustín Lizárraga en la ventana central del Templo de las Tres Ventanas. Fotografía derecha e inferior Hiram Bingham (1911) - Cortesía National Geographic Society.

Si bien Bingham ordenó borrar todos los grafitis que encontró a su retorno a la Llaqta en 1912, incluyendo el de Lizárraga de 1902, esto no fue para anular su memoria ya que en Inca Land lo menciona cuatro veces (1922: 219, 221, 226, 324) y en su obra más completa en dos oportunidades (1930: 108, 115). Asimismo, la referencia acerca del personaje que había escrito 33 veces su nombre en los mejores templos y edificios (1930: 19) no corresponde a Agustín Lizárraga en un intento de reclamar su «descubrimiento» sino a José María Ochoa, quien visitó el sitio con la expedición del profesor Cosio en enero de 1912 (Erdis 1911: 5; Cosio 1912a: 16).

Agustín Lizárraga falleció ahogado el 11 de febrero de 1912 tratando de cruzar a una isla en el río Vilcanota donde cultivaba maíz. Estaba en compañía de un niño que no lo pudo ayudar y su cuerpo no fue encontrado (Cosio 1912a: 13). Sus descendientes, que actualmente habitan en la zona de Inkaraqay, nos informaron que hubo más testigos del hecho y que sus restos fueron enterrados (Liberato Pedro Echegaray, comunicación personal 2014).

La Llaqta de Machupicchu nunca estuvo perdida y por ende nadie la descubrió. Bingham tuvo el privilegio y los medios para revelar a la ciencia y al mundo su existencia. Atribuirle el «descubrimiento científico» resulta totalmente válido, ya que si bien hubo varios personajes que arribaron a la Llaqta antes de 1911, la mayoría lo hizo con intenciones carentes de motivación científica. Resulta interesante notar que los hacendados de Huadquiña se sorprendieron cuando Bingham les enseñó las fotografías de la Llaqta y manifestaron que no tenían idea de que hubiese un sitio arqueológico de esa magnitud en aquel lugar (Bingham 1922: 221). Esta afir- 
mación resulta cuestionable ya que el sitio no era desconocido y desde el puente de San Miguel era posible divisar «[...] la silueta del pequeño edificio cerca de la piedra del intihuatana» (Bingham 1911b: 34) ${ }^{5}$, además de que no eran pocas las personas que transitaban regularmente por el camino entre Ollantaytambo y Santa Ana. La gente sabía de la existencia del sitio, algunas personas cultivaban en las terrazas de la Llaqta y otros incluso vivían allí (Cosio 1912a: 20), principalmente los campesinos de San Miguel (Cosio 1913: 24).

Las evidencias recuperadas por la EPY en la Llaqta de Machupicchu incluyen objetos modernos como una hoja rota de un cuchillo de hierro en la superficie de la cueva 9A. En la cueva 13A se encontró un anillo de metal blanco que Erdis consideró moderno, mientras que en el recinto $26 \mathrm{~A}$ se encontró un pequeño alambre de acero (Erdis 1912: 36). También se encontró una semilla de melocotón y un cuchillo de hierro decorado con tres agujeros en el recinto 32A. Además de un fragmento de hierro en la cueva 100 y dos cuentas de vidrio verde en la cueva 84 (Erdis 1912: 59g). Por su parte, Eaton encontró en la cueva 56 dos semillas de melocotón y un fragmento de óseo bovino (1916: 57) y en la cueva 100 un pedazo de hierro (1916: 79).

Resulta probable que este tipo de elementos culturales ajenos al mundo andino hayan sido intrusiones en el contexto producto de buscadores de tesoros, aunque en algunos casos, su presencia refuerza la hipótesis de que la Llaqta de Machupicchu estuvo poblada hasta alrededor de la segunda mitad del siglo XVI. De cualquier manera, estos objetos evidencian la ocupación del lugar luego de la invasión europea al Tawantinsuyu y la presencia de diversos personajes antes del «descubrimiento científico». Un tema que trataremos con mayor detalle en otra publicación.

\section{Las excavaciones de la EPY en 1912}

Las excavaciones de la EPY en la Llaqta de Machupicchu fueron ejecutadas bajo la supervisión de George Eaton y Ellwood Erdis entre julio y noviembre de 1912. Los trabajos se iniciaron el 20 de julio y consistieron en quemas, limpiezas, prospecciones y excavaciones. Se encontró material en superficie y algunas zonas bien definidas de desecho, principalmente correspondientes a fragmentos de cerámica (Bingham 1930: 17) como el caso de la sección 44A en el Sector Tres Portadas. La EPY de 1912 en la Llaqta también realizó registros, dibujos y tomó medidas de las estructuras y esculturas monolíticas más prominentes; como el caso del Intiwatana y de la escultura al interior de la cueva debajo del Templo del Sol (Erdis 1911: 5). Las quemas para la limpieza del sitio fueron recurrentes. Aparte de las que no fueron intencionales, durante los cuatro meses que duraron las labores se realizaron tres quemas y limpiezas generales (Bingham 1930: 20). Si bien el fotógrafo principal fue Bingham, durante las labores de la EPY de 1912 en la Llaqta, tanto Stevenson, 
Erdis e Eaton manejaron las cámaras, mientras que Bestor estuvo a cargo de revelar las fotografías.

Eaton publicó en 1916 el análisis de los restos óseos, que incluía la descripción, fotografías y un plano de ubicación de las cuevas, tumbas y/o excavaciones numeradas de la 1 a la $52^{6}$ de donde se había extraído los materiales en los alrededores de la Llaqta (Fig. 14). Por su parte, Erdis estuvo a cargo de las excavaciones dentro de la Llaqta y también de las tumbas o cuevas 53 a 107 luego de la partida de Eaton el 26 de agosto. Si bien la descripción de estas últimas fue incluida en la publicación de Eaton, el resto de información respecto a las excavaciones en la Llaqta fue publicada solo de manera referencial por Bingham (1930) y nunca se generó un plano de las excavaciones a cargo de Erdis en la Llaqta ${ }^{7}$, que como hemos referido anteriormente resulta indispensable para cualquier investigación a ejecutarse en el sitio.

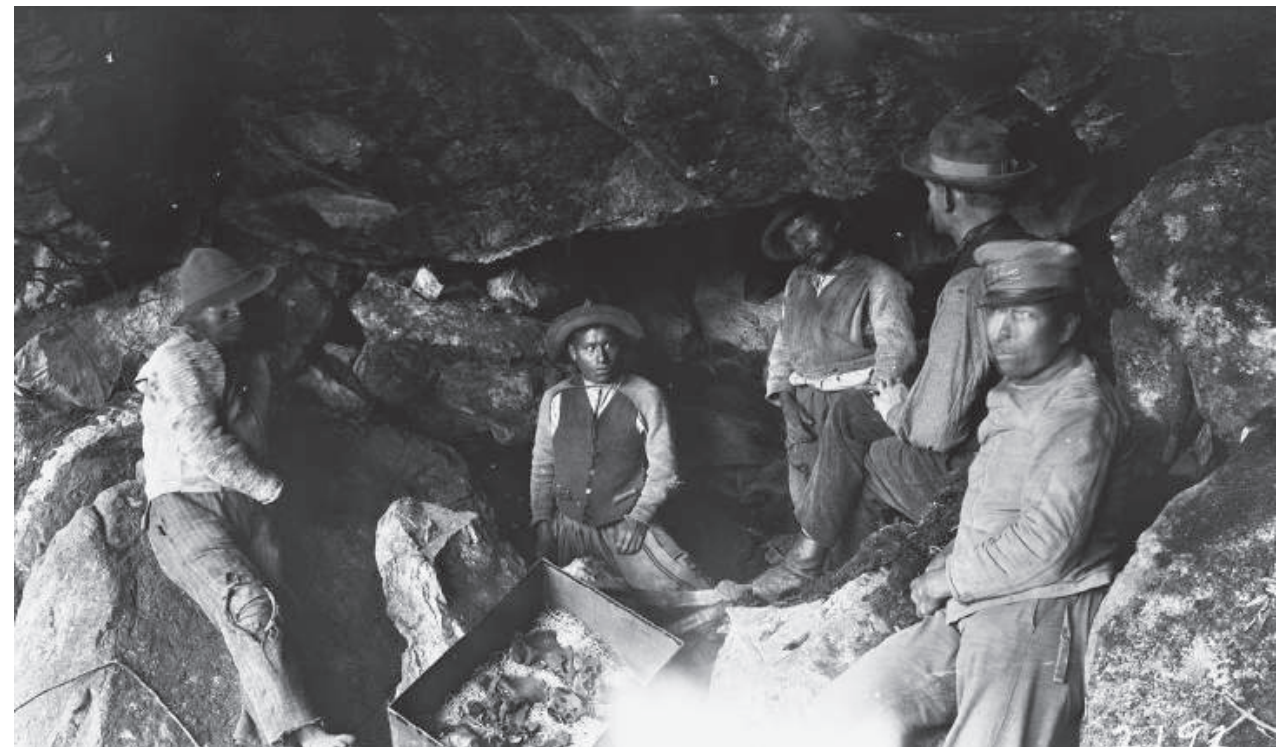

Figura 14. Una de las cuevas funerarias intervenidas por Eaton. De izquierda a derecha: Tomás Fuentes, Toribio Richarte, Anacleto Álvarez, George Eaton y el gendarme Jiménez. Fotografía Hiram Bingham (1912) - Cortesía National Geographic Society.

En 2003, Miller publicó un plano tentativo con la ubicación de las cuevas o tumbas de donde los asistentes de Erdis habían recuperado materiales arqueológicos (Fig. 15). La precisión con respecto a la ubicación de dichos lugares resulta relativa ya que Erdis se encontraba dedicado a los trabajos en la Llaqta y solo recibía información no muy precisa y bastante cuestionable con respecto a la ubicación de los lugares de donde determinados materiales habían sido extraídos por los equipos de Richarte, Álvarez y Fuentes (Eaton 1916: 3-4; Bingham 1930: 106; Guillén 1990), quienes ya habían sido entrenados por Eaton y sabían qué tipo de materiales eran 
procurados por la EPY. Por su parte, Erdis tuvo muchos problemas con los trabajadores cuya asistencia no era constante, algunos días había 30 personas laborando, mientras que otros ninguna. Asimismo, una vez que Eaton se retiró de la Llaqta, a Erdis le fue difícil controlar simultáneamente a las tres cuadrillas de buscadores de cuevas y al grupo dentro de la Llaqta (Erdis 1912: 57).

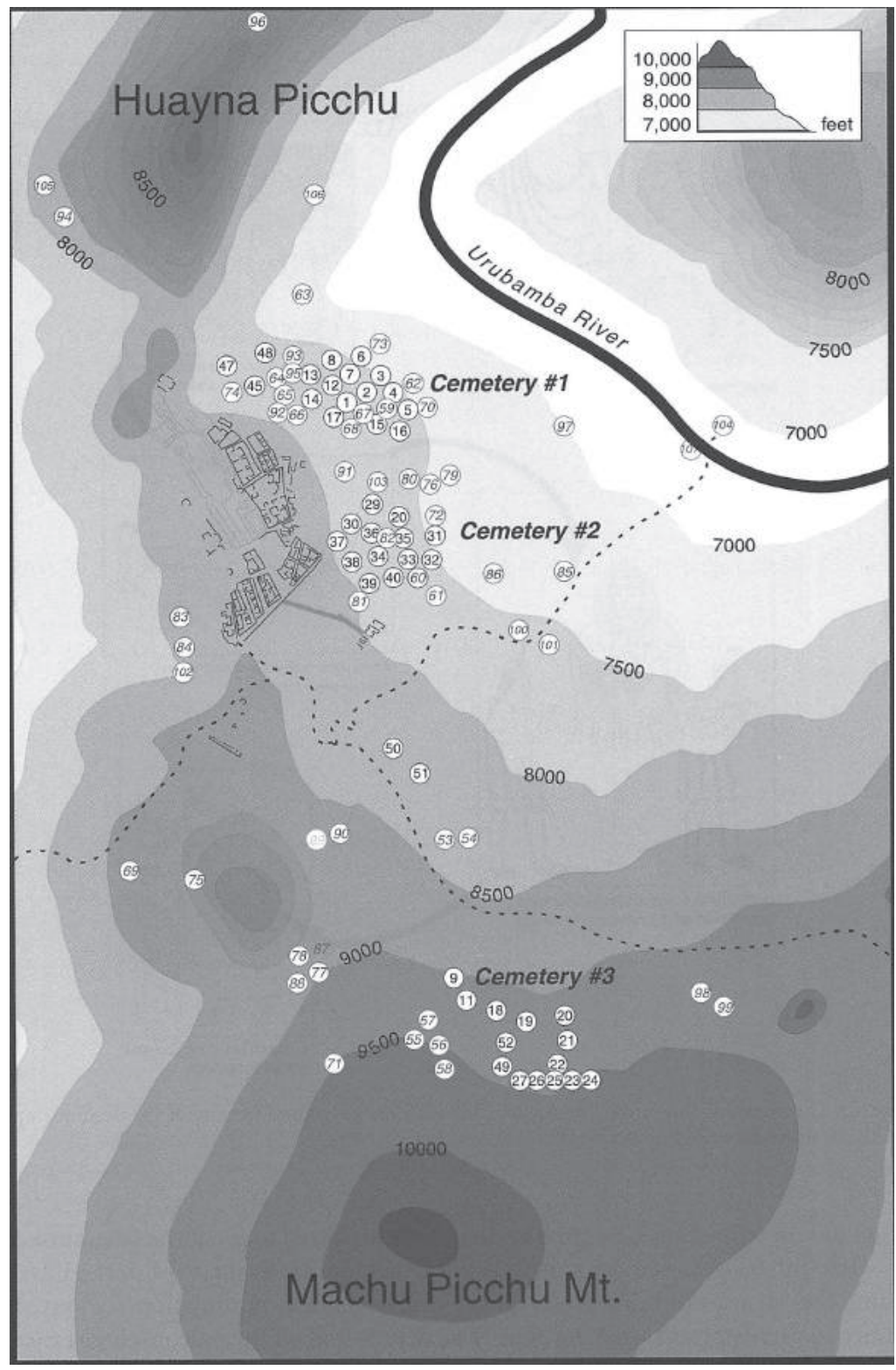

Figura 15. Plano de ubicación de las 107 cuevas sepulcrales, basado en el plano de Eaton y el diario de campo de Erdis. Tomado de Miller (2003). 
Debido a la inexistencia de un plano con las excavaciones ejecutadas por la EPY de 1912 y a la necesidad de saber con certeza los espacios o recintos que habían sido excavados, nuestro equipo se constituyó en la sección de Manuscritos y Archivos de la Biblioteca de la Universidad de Yale para analizar el diario de campo del ingeniero Ellwood Erdis, el cual es uno de los documentos de mayor importancia para el estudio de los trabajos ejecutados por la EPY en la Llaqta de Machupicchu.

El documento se encuentra en regular estado de conservación y cuenta con 149 páginas de papel cuadriculado escrito a lápiz. También existen dos copias mecanografiadas que no están completas. Los números de páginas empleados en el presente artículo corresponden al texto mecanografiado más completo que consiste de 95 páginas y cuyo texto ha sido cotejado con el original. Asimismo, los dibujos relacionados a arquitectura en las páginas $35,41,44,45$ y 71 del original no se presentan en las copias mecanografiadas (Fig. 16).

Es interesante notar que la primera página del documento original contiene el título E.C. Erdis y presenta dos frases en quechua y sus equivalencias en inglés: la primera indica «say nothing» y la siguiente «say nothing to anybody». El diario empieza el viernes 12 de julio de 1912 mientras se realizaban excavaciones en Saksaywaman y finaliza el domingo 17 de noviembre de 1912. Cabe mencionar que Erdis también participó en la última EPY de 1914-1915 y sus memorias quedaron plasmadas en cinco diarios de campo.

En general, el diario de campo de 1912 resulta un documento bastante confiable. Debemos tener presente que Erdis se refiere a sí mismo en tercera persona, brinda detalles personales, describe los pormenores de los trabajos e incluso sus suposiciones con respecto a algo son señaladas claramente como conjeturas. Asimismo, indica que todas las medidas son aproximadas (Erdis 1912: 17) y si bien sus descripciones no son del todo completas, ya que generalmente no se consideró la estratigrafía ni se definieron capas o niveles de ocupación y solo se presentan unos pocos dibujos de campo; Erdis intentó detallar con precisión la ubicación y/o la profundidad de sus hallazgos más importantes. También incluyó sugerencias para las próximas expediciones, notas importantes respecto a algunos sectores de la Llaqta y una relación con dibujos de los objetos arqueológicos de mayor relevancia. Durante sus últimos días en el monumento, Erdis se dedicó a contar el número de peldaños de las escalinatas (Fig. 17).

Es en función a las descripciones de dicho diario, muy a pesar de ciertas limitaciones y luego de un arduo trabajo de identificación tanto en campo como en gabinete, que hemos podido definir con gran precisión las áreas donde se ejecutaron excavaciones durante 1912 en los sectores Urbano y Agrícola de la Llaqta de Machupicchu (Fig. 18).

Si bien el presente es un estudio preliminar, el análisis del plano ha permitido notar que en algunos casos los arqueólogos han intervenido en espacios que ya habían sido excavados por la EPY de 1912. Esto ha generado serios problemas en cuanto a la 


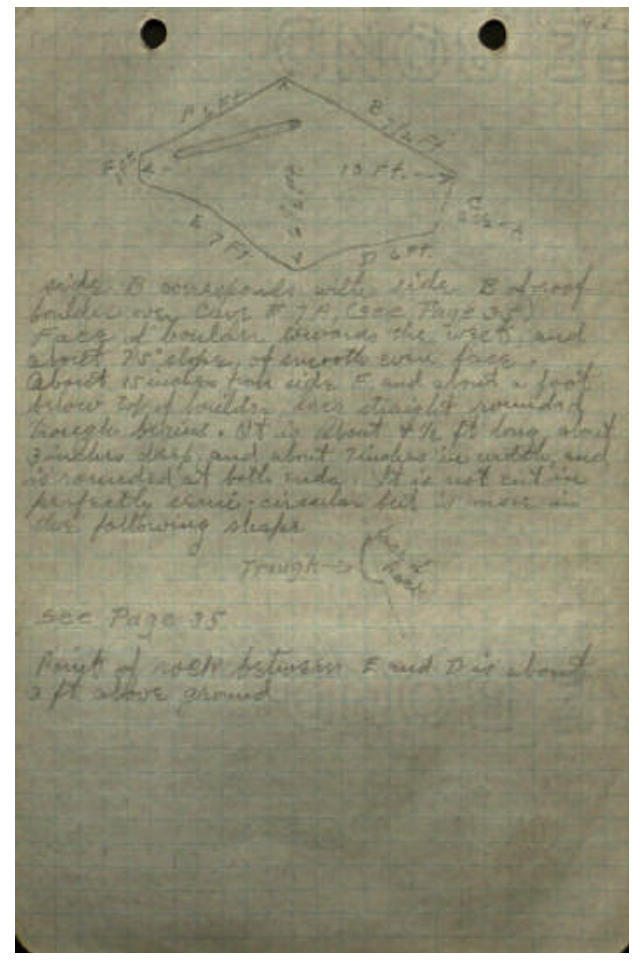

Figura 16. Página 41 del diario de campo de Erdis (1912).

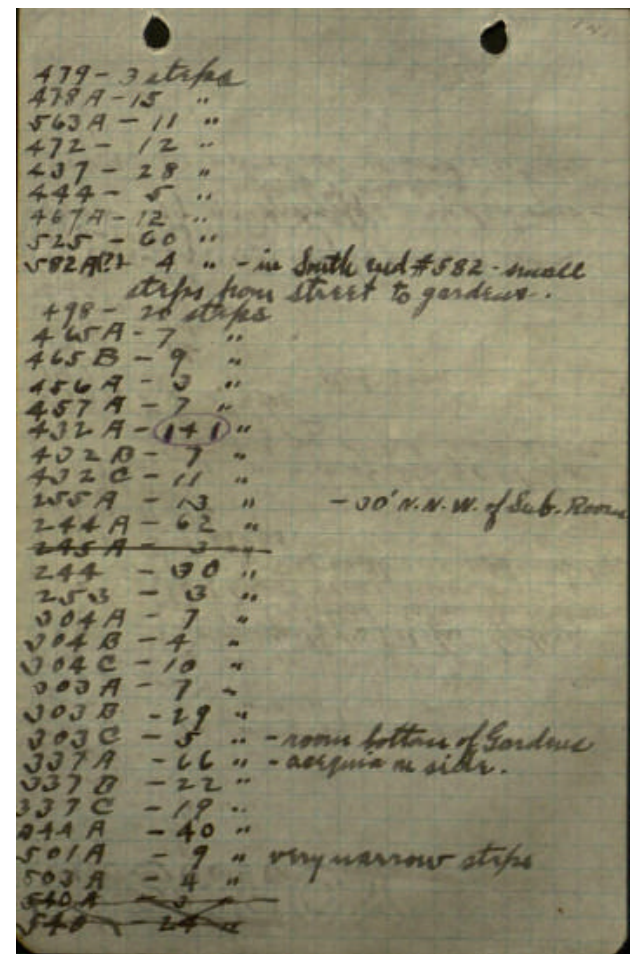

Figura 17. Página 141 del diario de campo de Erdis (1912).

interpretación del registro arqueológico, situación que viene siendo re-analizada por el equipo del Programa de Investigaciones Arqueológicas e Interdisciplinarias en el Santuario Histórico de Machupicchu (PIAISHM). Asimismo, algunas de las excavaciones arqueológicas que se plantearán para la siguiente temporada de investigaciones del PIAISHM serán ubicadas en lugares adyacentes a las excavaciones de la EPY con la finalidad de contextualizar de alguna manera los hallazgos de 1912.

Por una parte, la estratigrafía en la Llaqta de Machupicchu resulta mucho menos compleja que en otros sitios arqueológicos que presentan distintas fases de ocupación, ya que solo se tiene evidencia de una ocupación netamente Inka Imperial. Sin embargo, resulta evidente la presencia humana en la zona desde épocas anteriores a la ocupación Inka (Sarmiento de Gamboa 1942: 179-180 [1572]; Valcárcel 1929: 101-102; Astete et al. 2016: 75; Bastante y Fernández 2017). Por otro lado, se tienen limitaciones con respecto a la integridad de los contextos debido tanto a las condiciones medioambientales como por acción de la fauna y si bien la Llaqta fue cubierta por la vegetación que crece con asombrosa rapidez ${ }^{8}$ (Fig. 19 y 20), ésta fue saqueada sistemáticamente desde su abandono total ocurrido durante la segunda mitad del siglo XVI. 


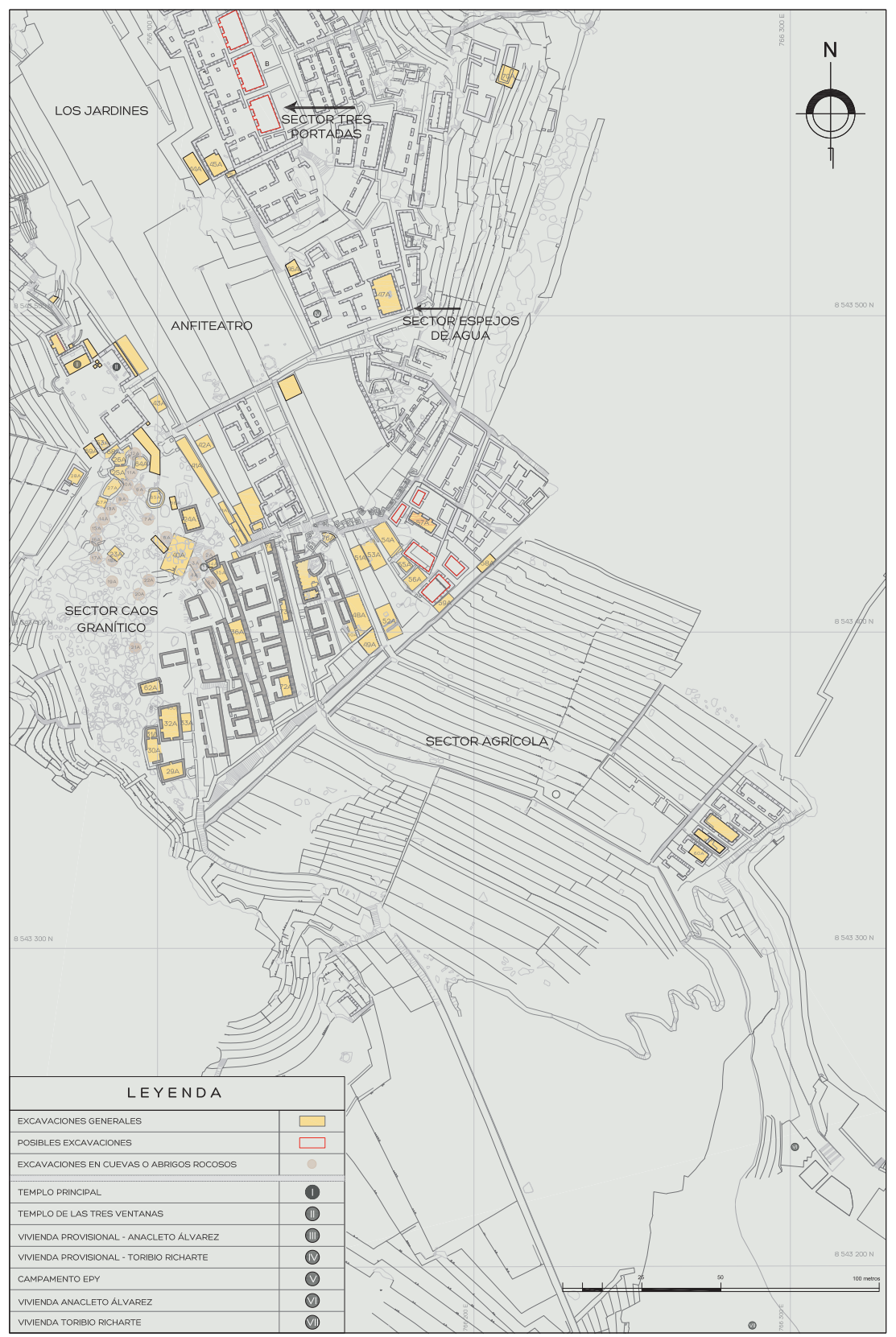

Figura 18. Excavaciones realizadas por la EPY en la Llaqta de Machupicchu durante el año 1912 (color amarillo). Los recintos delimitados con color rojo fueron probablemente excavaciones bastante superficiales. Plano elaborado en base a las descripciones del diario de campo de Erdis. Las cuevas/ abrigos rocosos excavados se encuentran marcados por círculos de color beige. El número I corresponde al Templo Principal, el II al Templo de las Tres Ventanas, el III a la vivienda provisional de Álvarez, el IV a la vivienda provisional de Richarte, el V al campamento de la EPY, el VI a la vivienda de Álvarez y el VII a la vivienda de Richarte. 
La información proporcionada por Bingham sugiere que durante la EPY de 1912 se excavó prácticamente toda la Llaqta de Machupicchu (1930: 16, 17). Sin embargo, el plano elaborado en función a las descripciones en el diario de campo de Erdis no concuerda con algunas referencias a excavaciones brindadas por Bingham (1912, 1930), quien en algunos casos no presenta información fidedigna. Bingham menciona haber realizado excavaciones en lugares que, de acuerdo a lo plasmado por Erdis en su diario, nunca se ejecutaron, como es el caso del Templo de las Tres Ventanas, los dos recintos en la parte superior de la pirámide del Intiwatana o de la totalidad de los recintos del Sector de Espejos de Agua (1930: 12, 17), como veremos en detalle más adelante.

Para una lectura más adecuada, el plano que presentamos (Fig. 18) considera la misma codificación que Erdis empleó en sus descripciones para las áreas, recintos y/o cuevas excavadas al interior de la Llaqta de Machupicchu, aunque algunas excavaciones no fueron codificadas. El mayor porcentaje de lugares donde se excavó se encuentran identificados en el plano con color amarillo. Por su parte, las excavaciones en los recintos delimitados con color rojo han sido ubicadas en base a referencias poco precisas.

A manera general, lo que Erdis refiere en su diario de campo como «los jardines» es lo que actualmente se denomina la Plaza Principal y el Sector Llamakancha; el «anfiteatro» es la parte de la Plaza Principal entre el Templo de las Tres Ventanas y el Sector Espejos de Agua, mientras que el denominado «palacio de Richarte» está identificado en el plano con el número IV. El cruce de información de Bingham

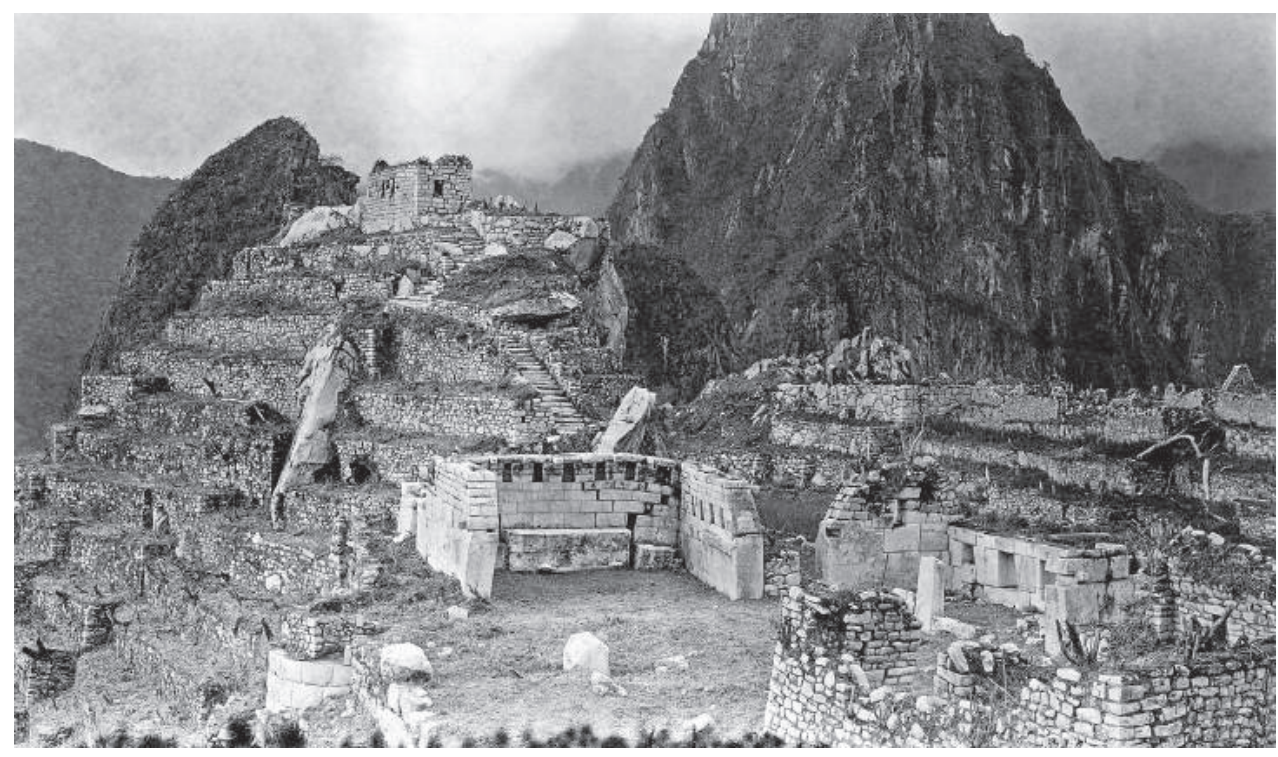

Figura 19. Fotografía tomada por Bingham luego de la tercera y última quema/limpieza general de la Llaqta en 1912. 


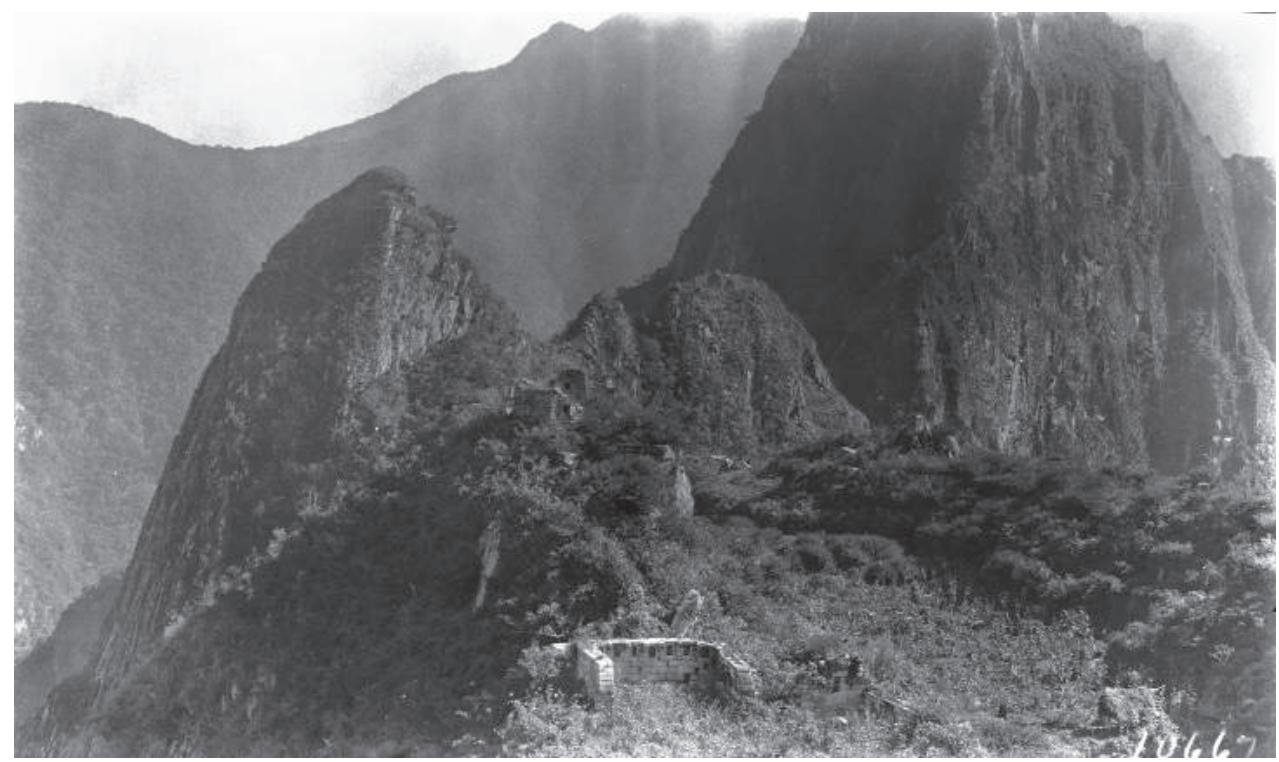

Figura 20. Fotografía tomada por Bingham en 1915 para evidenciar el abrumador crecimiento de la vegetación - Cortesía National Geographic Society.

(1930), Erdis (1912), Cosio (1912 a, b) e Eaton (1916) nos ha permitido identificar la ubicación de las viviendas de las familias de campesinos que habitaban el lugar cuando llegó Bingham en 1911, tanto la de Toribio Richarte (número VII) como la de Anacleto Álvarez (número VI) y sus viviendas provisionales al interior de la Llaqta (números IV y III, respectivamente). Para el caso Tomás Fuentes, resulta más probable que su vivienda principal haya estado en el Sector Intiwatana (Hidroeléctrica - $\mathrm{km} \mathrm{122)} \mathrm{y} \mathrm{no} \mathrm{en} \mathrm{el} \mathrm{monumento} \mathrm{o} \mathrm{sus} \mathrm{alrededores} \mathrm{inmediatos.}$

Con contadas excepciones, las excavaciones no profundizaron mas allá de los $60 \mathrm{~cm}$, en algunos casos la limpieza que se hizo para llegar hasta el piso de ocupación Inka fue de $30 \mathrm{~cm}$. Sin embargo, Erdis notó que al excavar cerca de los muros de la Plaza de los Templos, que presentaban un promedio entre 60 y $90 \mathrm{~cm}$ de cimentación, se podían encontrar fragmentos de cerámica a unos $15 \mathrm{~cm}$ debajo de la base (Erdis 1912: 10). Lo que puede ser interpretado como ofrendas durante el proceso constructivo. De esta manera, fue en base a los hallazgos (cantidad y calidad de los objetos) que se decidía ampliar, profundizar o abandonar determinada excavación. También se recogió material de superficie en diferentes partes del sitio, principalmente fragmentos de cerámica. Cuando por determinada razón Erdis no pudo trabajar, Bestor (1912) se hizo cargo de supervisar las excavaciones y hubo días con lluvias copiosas que no permitieron realizar ninguna labor.

Debido a su evidente importancia arquitectónica, el primer recinto excavado fue el Templo Principal (Fig. 21). Las hipótesis relacionadas a la capa de arena blanca en el piso de este templo y su analogía con el Aucaypata de Cusco (Reinhard 


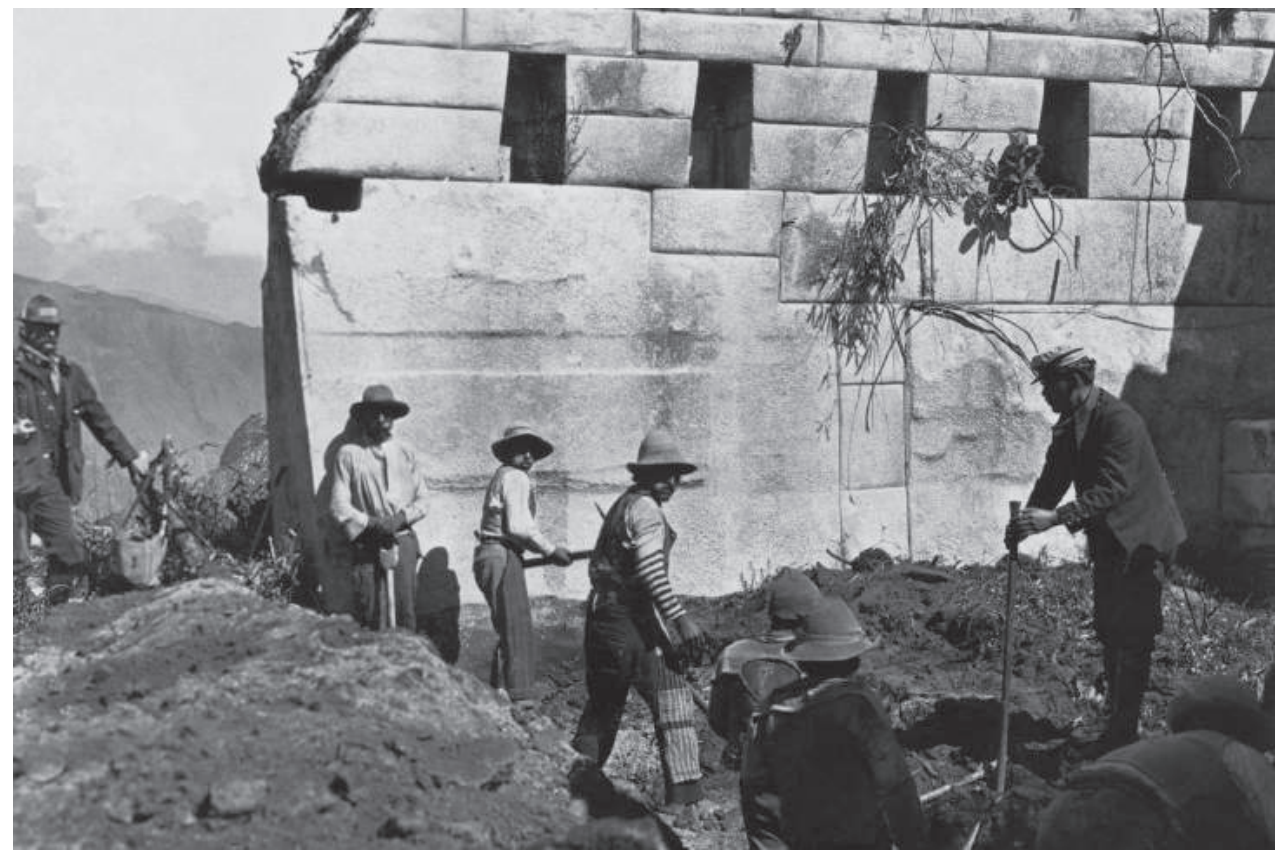

Figura 21. La primera excavación de la EPY en Llaqta de Machupicchu fue en el Templo Principal. George Eaton en el extremo izquierdo, Melquiades Pareja Sotomayor en el extremo derecho. Los otros personajes no han sido identificados. Fotografía Hiram Bingham (1912) - Cortesía National Geographic Society.

1991: 60-61; 2007: 58-59) resultan inválidas, ya que la presencia de «arena blanca gruesa» descrita por Bingham (1930: 58) no correspondía a una capa sino simplemente a la meteorización del granito (Erdis 1912: 5), como también se ha evidenciado en excavaciones arqueológicas posteriores. Asimismo, a pesar de que Bingham indica que no se halló material cultural (1930: 12), si lo hubo en superficie y correspondía a fragmentos de cerámica llana (Erdis 1912: 5; Bingham 1912: 10).

A manera general, durante las labores de la EPY en la Llaqta se encontraron numerosos objetos líticos, principalmente alisadores, percutores y/o piedras martillo, cerámica doméstica y ceremonial. También se hallaron argollas, ornamentos y objetos circulares de esquisto de distintos tamaños, «pedazos de pintura», objetos de bronce como anillos, hachas y tupus, cabezas en forma de aves correspondientes a escudillas, aplicaciones/apéndices de cabezas de felinos y serpientes, restos óseos humanos y animales, y en menor medida ruecas para hilar, agujas, dientes animales, objetos de obsidiana y algunos cuarzos cristalinos.

No todo lo encontrado se recogió, hubo objetos líticos que debido a su peso no fueron recolectados, además de algunos restos óseos y varios fragmentos de cerámica llana que se dejaron donde fueron encontrados o fueron apilados en otros lugares. Entre finales de octubre y principios de noviembre, Stephenson y Erdis realizaron la última discriminación de los fragmentos de cerámica recuperados, 


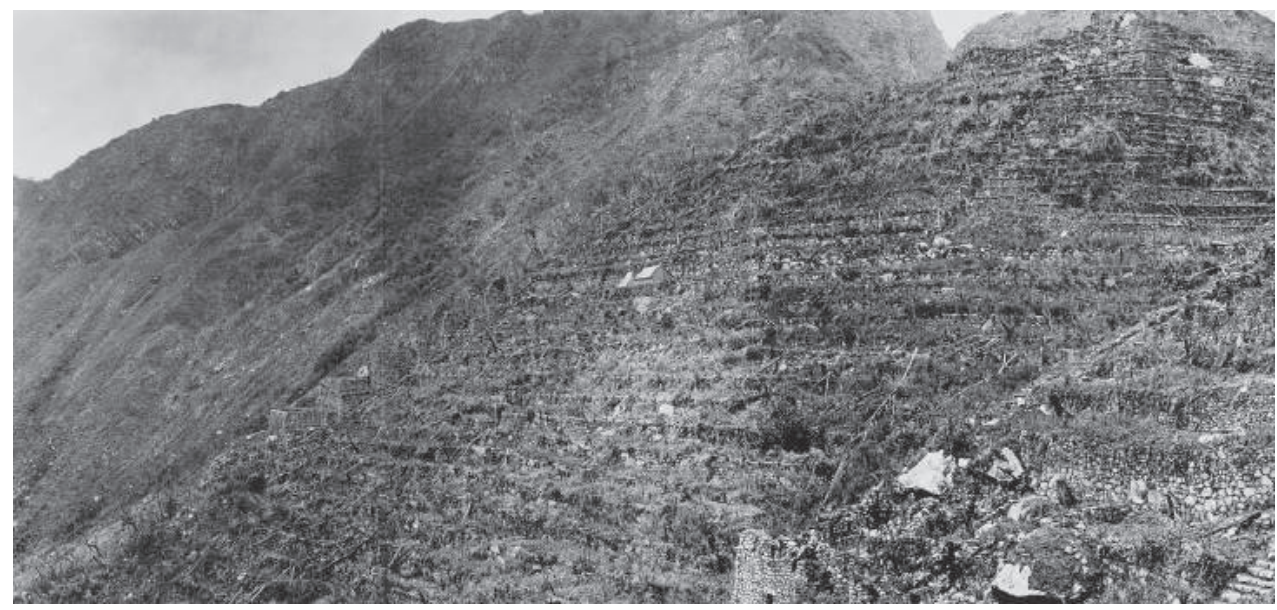

Figura 22. Ubicación del campamento de la EPY de 1912 en el Sector Agrícola de la Llaqta de Machupicchu (centro de la imagen). Fotografía Hiram Bingham - Cortesía National Geographic Society.

descartando cerca al campamento (Fig. 22) los que no iban a llevar. Antes de ser transportados, los materiales fueron empacados en papel y guardados en cajas o sacos (Erdis 1912: 50).

\section{Ubicación de algunos objetos excavados por Erdis en 1912}

Uno de los principales objetivos de la EPY fue el de recuperar objetos arqueológicos. Bingham refirió que el sector actualmente denominado Caos Granítico (al que nombra como la zona o cementerio de la Roca de la Serpiente) fue el más prolífico (1930: 15-17) (Fig. 23). Esto se encuentra en relación a la cantidad y calidad de los objetos hallados en las excavaciones. Como ejemplo tenemos el cuchillo de bronce del pescador (Fig. 24), probablemente procedente de la costa norte del Perú (Owen 2012: 108-111) y actualmente en exhibición en el Museo Machupicchu de la Casa Concha en Cusco. Este objeto fue ubicado por Erdis a una profundidad de $45 \mathrm{~cm}$ en la esquina noroeste del recinto 24A (1912: 31) (Fig. 25). La excavación en este recinto no evidenció ningún resto óseo pero si numerosos artefactos de cerámica, esquisto, granito, piedras martillo, pulidores, un objeto de madera, metales y una semilla de lúcuma (Erdis 1912: 21-22).

El diario de campo de Erdis también brinda algunos datos generales de importancia, como la referencia a que los restos óseos eran escasos en los recintos, que existía mucho carbón disperso en el suelo de las cuevas y que en algunos casos los fragmentos de un mismo objeto se hallaron en diferentes recintos, como la caja de piedra con diseños ubicada en los recintos 25A y 26A (Fig. 23, 26 y 32). En otros casos incluso a una distancia de hasta 24 metros, como la caja de piedra con diseños 
(Fig. 27) ubicada en las secciones $40 \mathrm{~A}$ y 41A (1912: 14, 34-35, 39, 56) (Fig. 23, 28 y 29). Erdis definió a la sección 40 A como un «botadero» debido a que encontró objetos enteros y fragmentos de distintos tipos. Tanto en esta sección como en la 41 A se halló una gran cantidad de materiales, entre otros, algunos discos de plata (Erdis 1912: 51-57) (Fig. 30).

De esta manera, es en base a las descripciones de Erdis que se ha identificado en el plano tanto la ubicación de las excavaciones y en cuáles fueron hallados un porcentaje considerable de los objetos que se encuentran en exposición en el Museo Machupicchu de la Casa Concha, como el caso de un cuchillo de bronce que Erdis describe como un «tupu... con 6 rayos en la cabeza» (1912: 36) (Fig. 31), excavado en el recinto $26 \mathrm{~A}$ (Fig. 23 y 32 ).

La EPY de 1912 recuperó alrededor de 200 objetos de metal de la Llaqta de Machupicchu (Burger y Salazar 2012: xi-xii). Entre objetos de metal completos, en la cueva 9A se recuperó un disco de bronce de «[...] dos pulgadas de diámetro y una proyección cuadrada

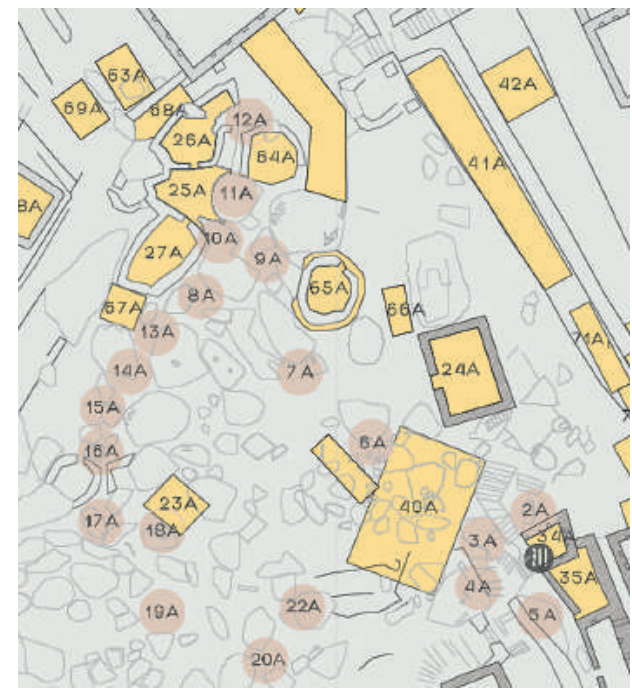

Figura 23. Excavaciones en el Sector Caos Granítico.

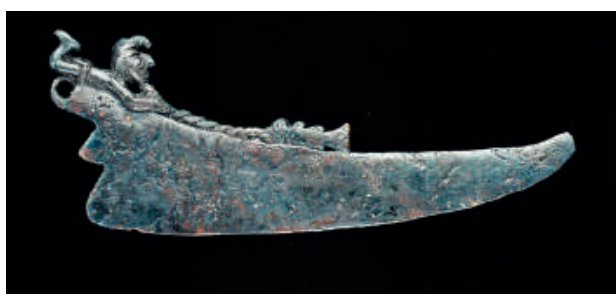

Figura 24. Cuchillo/dije ceremonial excavado por Erdis en el recinto 24A durante la EPY de 1912. Fotografía tomada de Salazar y Burger (2004). con agujero [...]» (Erdis 1912: 19) (Fig. 23, 33 y 34). Mientras que en el recinto 34A (Fig. 23 y 35) se encontró un brazalete de bronce a $30 \mathrm{~cm}$ de profundidad (Erdis 1912: 45) (Fig. 36).

Sumado a los numerosos hallazgos de objetos de metal en la Llaqta, en la sección 40A también se encontró un pedazo de bronce fundido (Erdis 1912: 53), que considerando los otros hallazgos de la EPY relacionados a labores metalúrgicas, sus respectivos análisis (ver Burger y Salazar 2012) y de las investigaciones arqueológicas de los últimos años (Fig. 37), queda definido que hubo una producción metalúrgica en la Llaqta de Machupicchu (Mathewson 1915; Gordon y Rutledge 1984; Burger 2004; Salazar 2007; Gordon 2012; Owen 2012) pero destinada exclusivamente para su uso local (Bastante y Fernández 2017).

Aparte de la gran cantidad de objetos de cerámica encontrados y de los que se pudieron armar a partir de fragmentos; en los recintos 34A (Fig. 35), 31A 


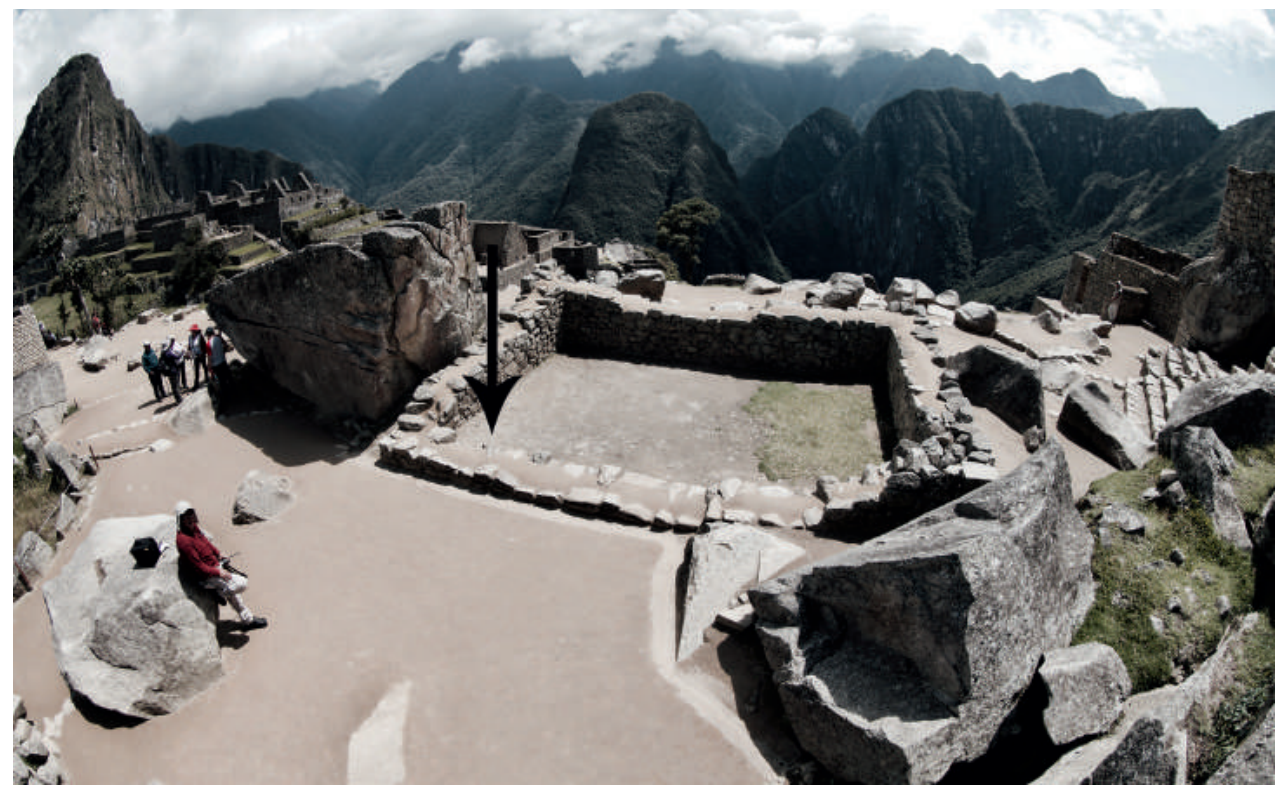

Figura 25. Recinto $24 \mathrm{~A}$ donde Erdis excavó el cuchillo/dije ceremonial del pescador en la esquina marcada con la flecha. Fotografía José Bastante.

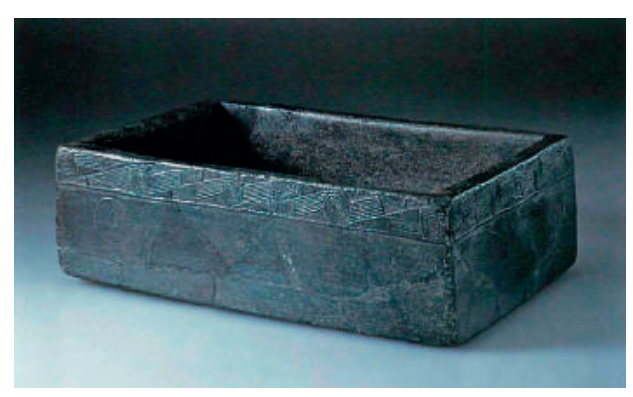

Figura 26. Los fragmentos del objeto fueron hallados en los recintos 25A y 26A. Fotografía tomada de Salazar y Burger (2004).

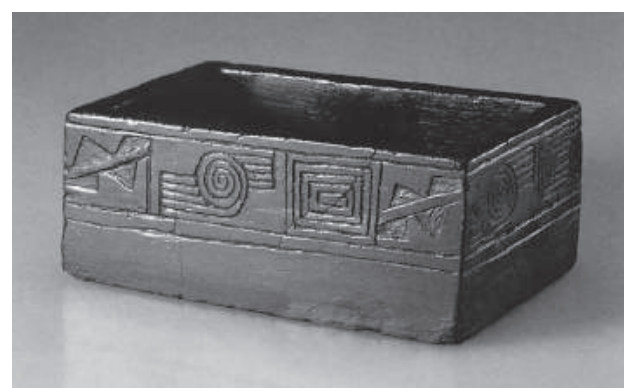

Figura 27. Los fragmentos del objeto fueron hallados en las secciones $40 \mathrm{~A}$ y $41 \mathrm{~A}$. Fotografía tomada de Salazar y Burger (2004).
(Fig. 39), 72A (Fig. 40), en la sección 40A (Fig. 23 y 29) y en la cueva 93 se encontraron dados de cerámica (Fig. 38). Estos serían pishkas, objetos que durante épocas prehispánicas probablemente sirvieron como instrumentos para la comunicación entre los sacerdotes andinos y las wakas (Rowe 1946: 288-289; Gentile 1998).

Por su parte, si bien las condiciones medioambientales en la Llaqta de Machupicchu no permiten una adecuada conservación de los textiles, Eaton (1916) halló porciones de éstos en algunas cuevas mortuorias mientras que Erdis halló pequeños fragmentos adheridos a tupus $(1912$ : 50, 61) como lo evidenciado en los análisis de la mayor parte de tupus de la Colección Machupicchu (Owen 2012: 8) y los encontrados en posteriores investigaciones arqueológicas; cuyo estudio indica que corres- 


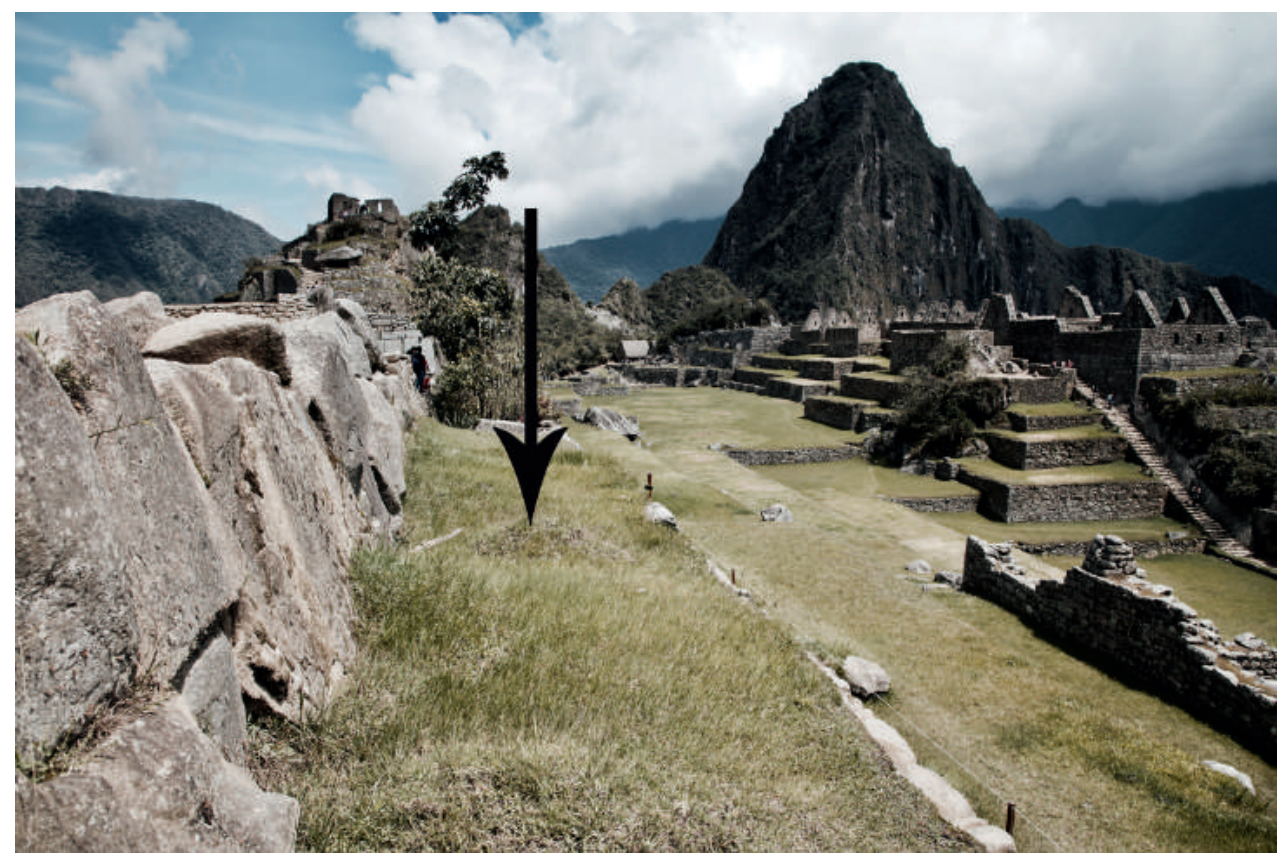

Figura 28. Terraza de andén que corresponde a la sección 41A. Fotografía José Bastante.

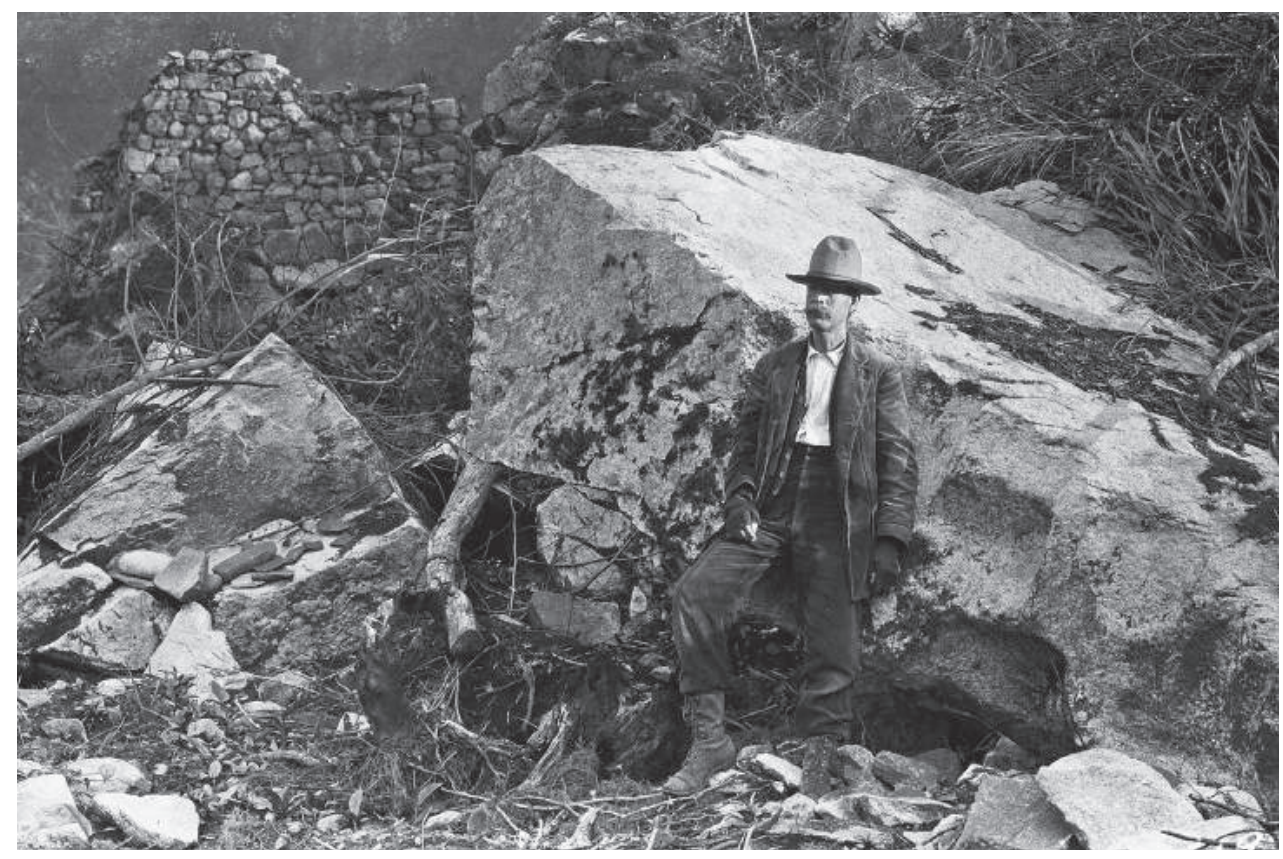

Figura 29. Ellwood Erdis en la sección $40 \mathrm{~A}$ del Sector Caos Granítico de la Llaqta. Fotografía Hiram Bingham (1912) - Cortesía National Geographic Society. 


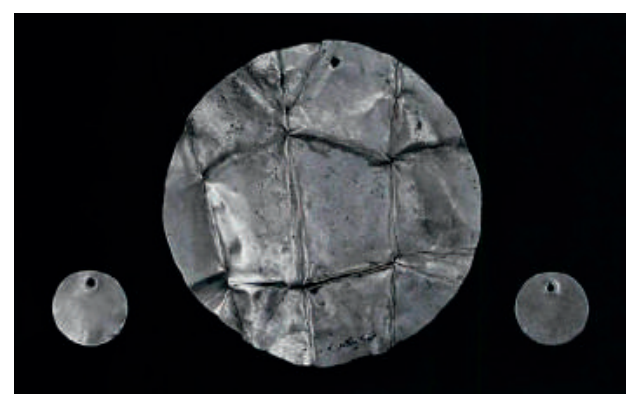

Figura 30. Los objetos pequeños de plata en los extremos fueron hallados en la excavación de la sección 40A. El objeto central fue excavado en la sección 41A. Fotografía tomada de Salazar y Burger (2004).

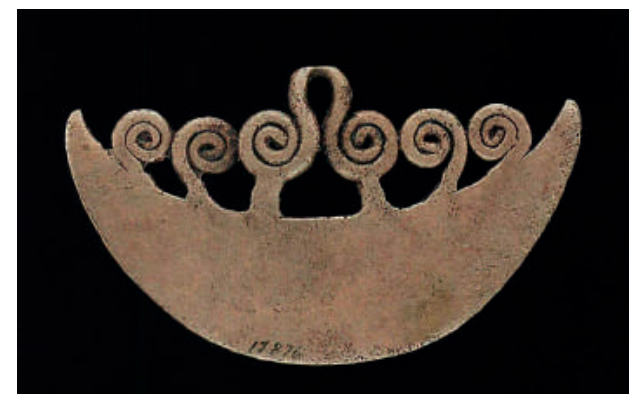

Figura 31. Cuchillo/dije de bronce encontrado en el recinto 26A. Fotografía tomada de Salazar y Burger (2004).

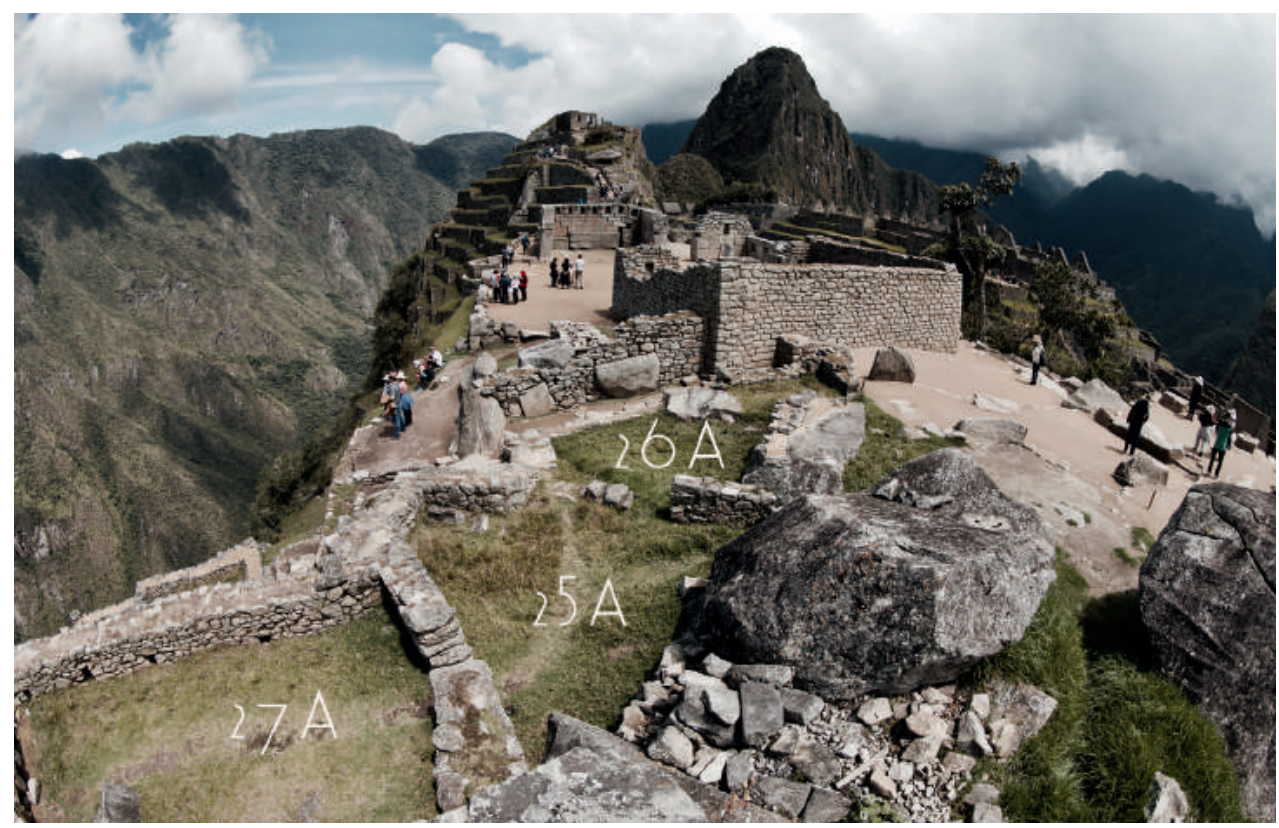

Figura 32. Ubicación de los recintos 25A, 26A y 27A en relación a la Plaza de los Templos. Fotografía José Bastante.

ponden a fibras de camélidos (vicuña/alpaca) y algodón (Bastante 2016b). También halló un textil en el mango de un cuchillo recuperado a $30 \mathrm{~cm}$ de profundidad en la excavación $44 \mathrm{~A}$ y sugiere correctamente que esto permitiría una mejor maniobrabilidad del instrumento (Erdis 1912: 59g). Además se encontraron fragmentos de cuerdas y en algunos contextos mortuorios textiles llanos como el de la cueva 84, donde los restos óseos tenían ligamentos e incluso carne adheridos (Erdis 1912).

Considerando la presencia de objetos relacionados a labores textiles como ruquis y fusayolas (Fig. 41) que fueron encontrados durante 1912 (Eaton 1916; 
Miller 2013: 51-76) y que se han seguido hallando en distintos espacios de la Llaqta (Fig. 42), además de la presencia de ambientes de tipo wayrana; resulta evidente que hubo una producción textil destinada, al igual que la producción metalúrgica, a un uso local.

\section{Excavaciones no definidas}

Si bien Erdis menciona haber realizado limpiezas y excavaciones en el Sector Tres Portadas, resulta probable que los recintos a los que alude que fueron excavados y donde no se encontró

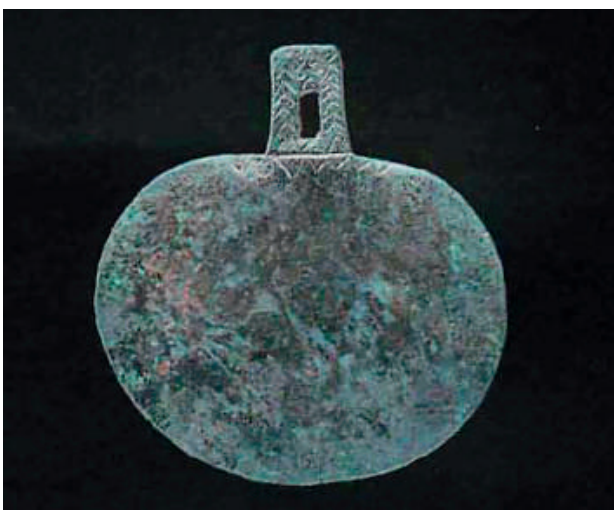

Figura 33. Ornamento de bronce encontrado en la cueva 9A del Sector Caos Granítico (Canteras o Zona de la Roca de la Serpiente). Fotografía tomada de Salazar y Burger (2004). material cultural (1912: 13, 59i) hayan sido los tres de mayores dimensiones ubicados al este de cada kancha e indicados en el plano con color rojo (Fig. 43). En base a las evidencias de investigaciones posteriores se ha confirmado que las excavaciones de Erdis en estos recintos fueron bastante superficiales.

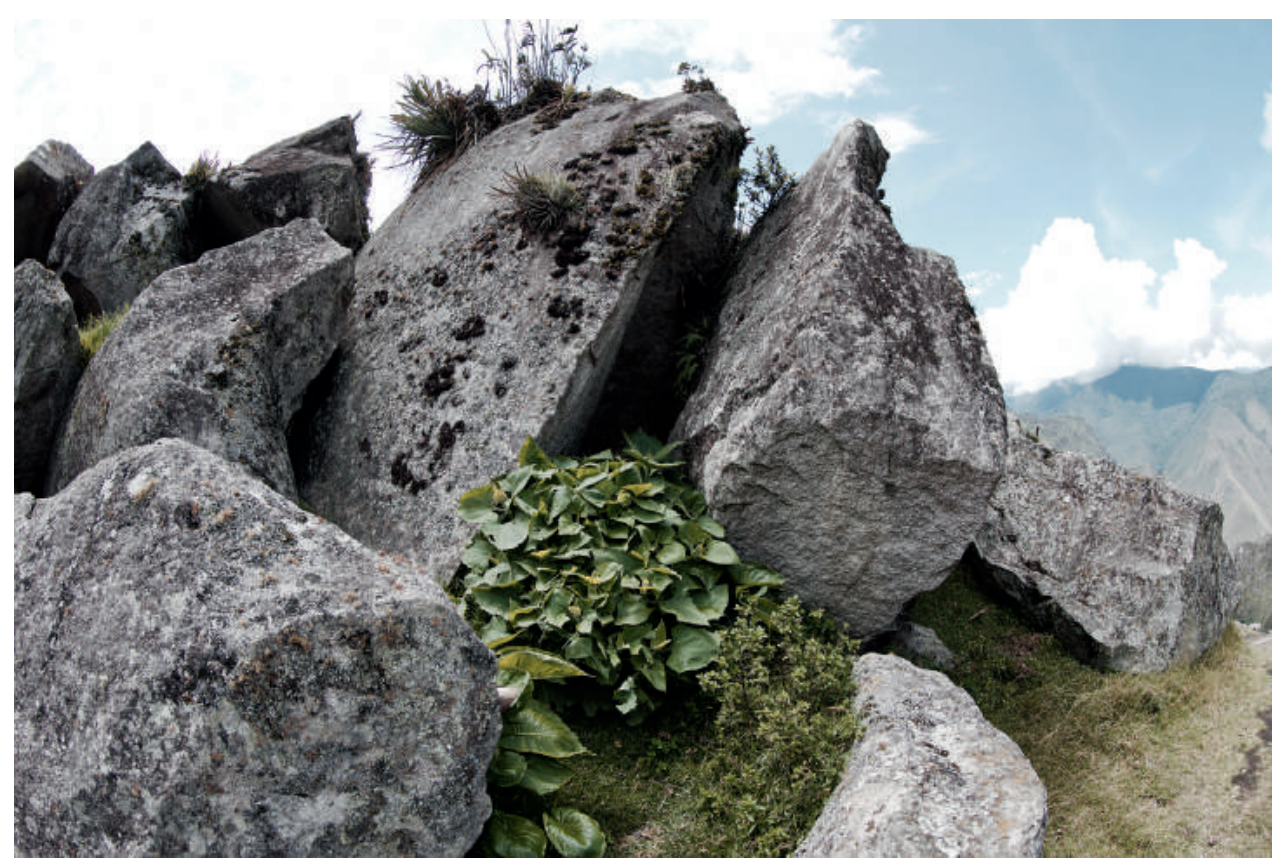

Figura 34. Cueva 9A en el Sector Caos Granítico (Canteras o Zona de la Roca de la Serpiente). Fotografía José Bastante. 


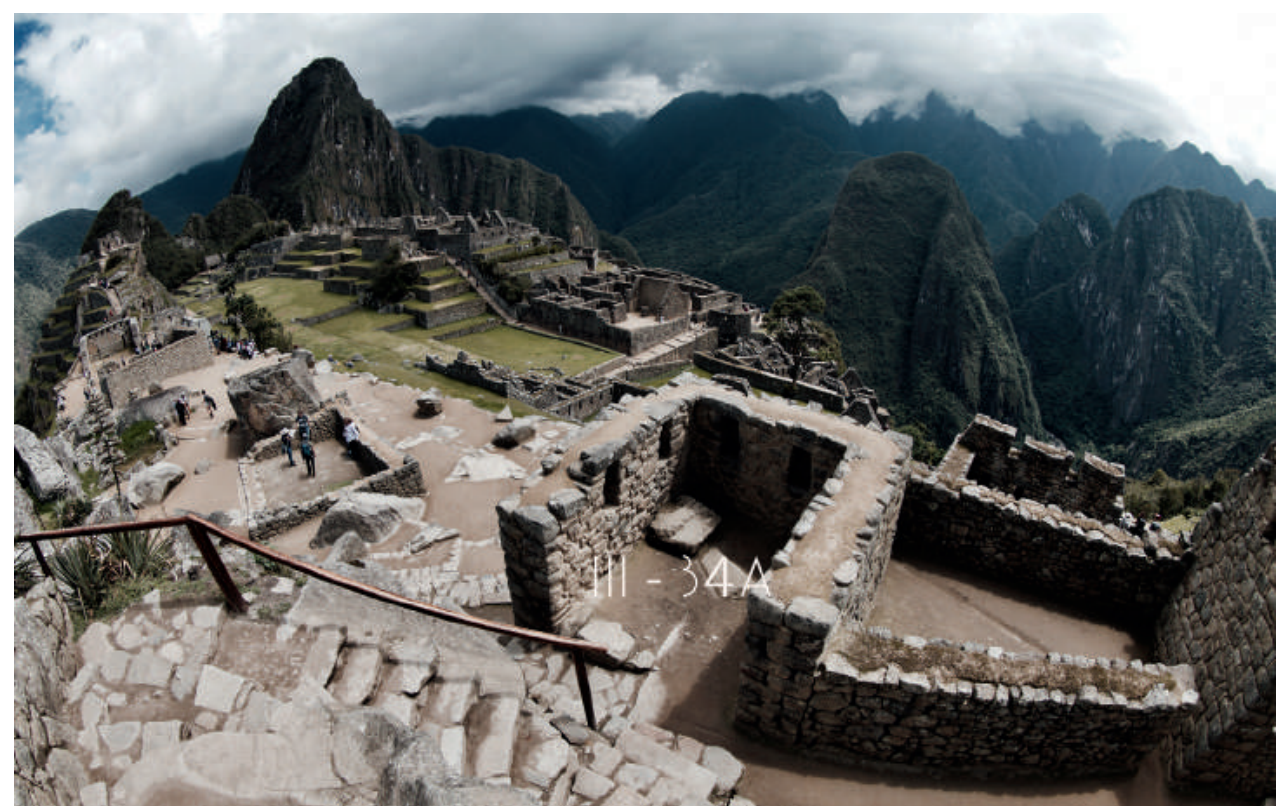

Figura 35. Ubicación del recinto 34A, que también fue la casa provisional de Anacleto Álvarez (No III en el plano - Fig. 18). Fotografía José Bastante.

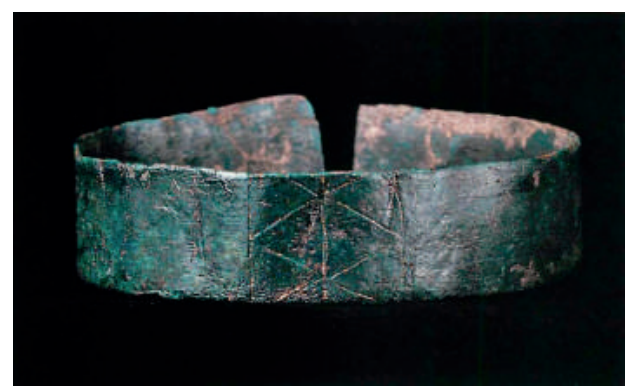

Figura 36. Brazalete de bronce procedente del recinto 34A. Fotografía tomada de Salazar y Burger (2004).

Con respecto a las excavaciones que Bingham menciona haber ejecutado (1930), el cruce de información con el diario de campo de Erdis nos ha permitido definir que no se ejecutaron excavaciones en el Templo de las Tres Ventanas donde de acuerdo con Bingham no se halló nada (1930: 12). La referencia a la excavación en dicho templo no fue al interior como lo indica Bingham sino entre éste y el Templo Principal tal como ha sido consignado en el plano que presentamos (Fig. 44). El Templo de las Tres Ventanas fue limpiado hasta el nivel de piso Inka donde se encontraron tres piedras con agujeros y alrededor de una docena de fragmentos de cerámica, dos de éstos presentaban incisiones (Erdis 1911: 9). Bingham también indica que se excavó el muro semicircular al oeste de la Plaza de los Templos (1930: 66) pero no existe referencia al respecto en el diario de campo de Erdis.

Por su parte, en la zona de la pirámide del Intiwatana, aparte de una pequeña excavación cerca a la escalinata de subida y el recojo de pulidores líticos en el lado sur, no se realizaron excavaciones (Bingham 1930: 17, 56; Erdis 1912: 64). 


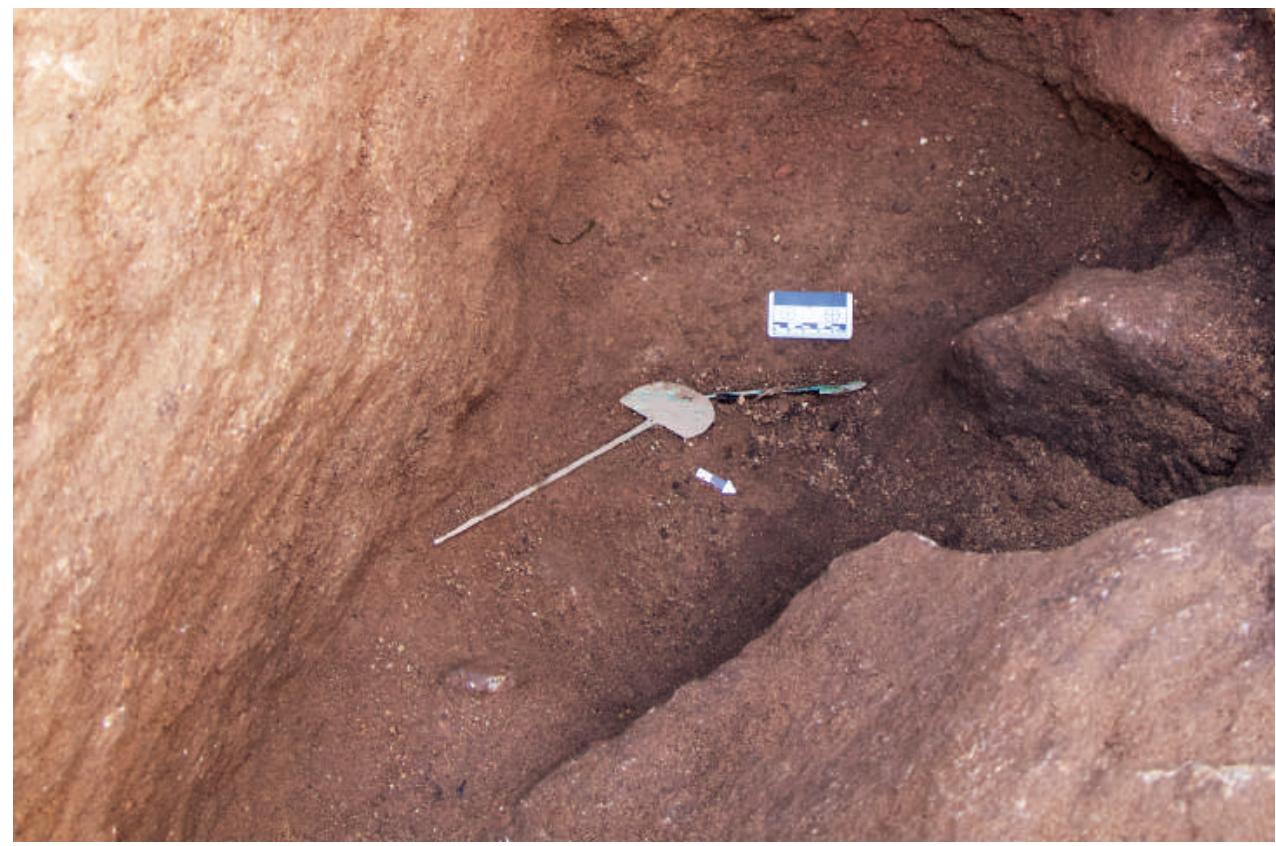

Figura 37. Tupus de aleación plata-cobre recuperados durante la Temporada PIAISHM 2016 (UE12) en el Sector Espejos de Agua. Fotografía José Bastante.

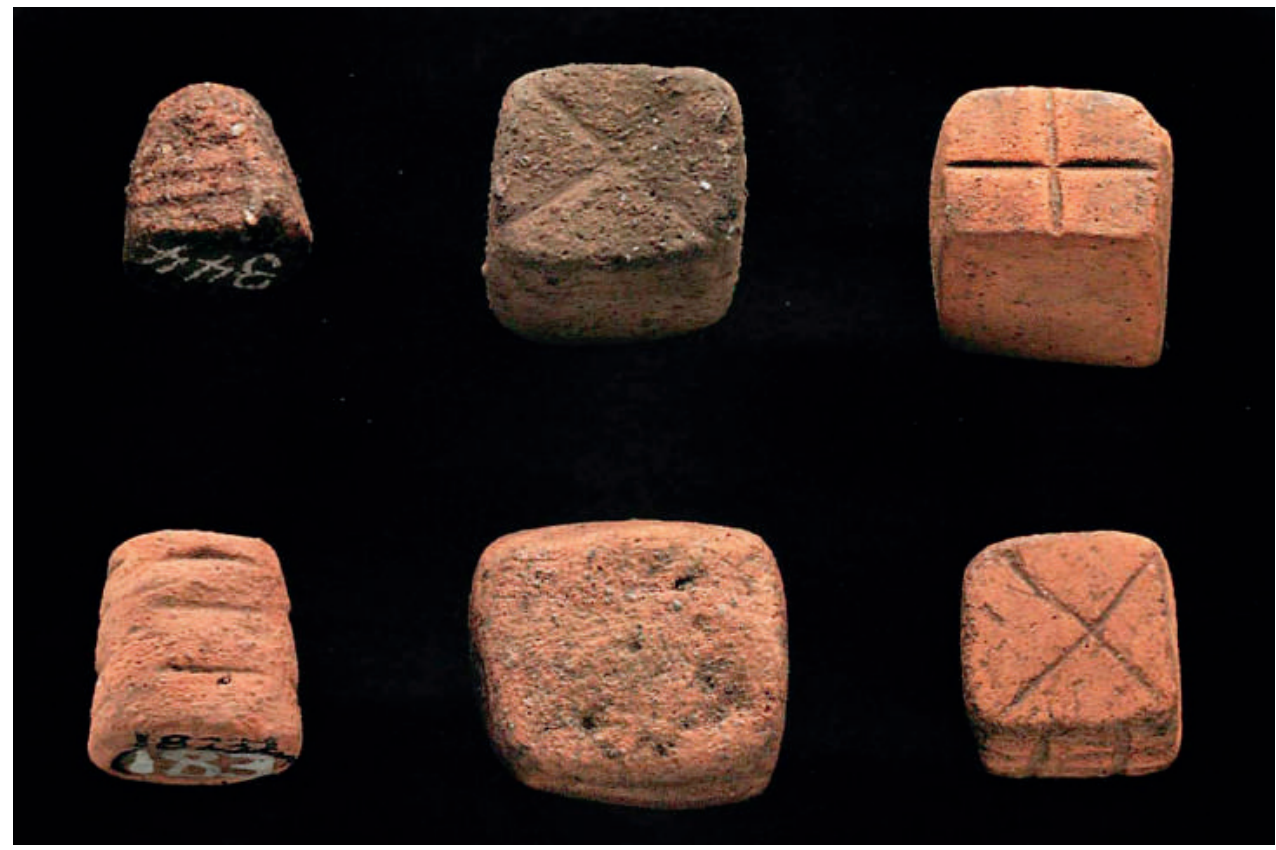

Figura 38. Pishkas halladas durante las excavaciones de la EPY en 1912. Fotografía tomada de Salazar y Burger (2004). 


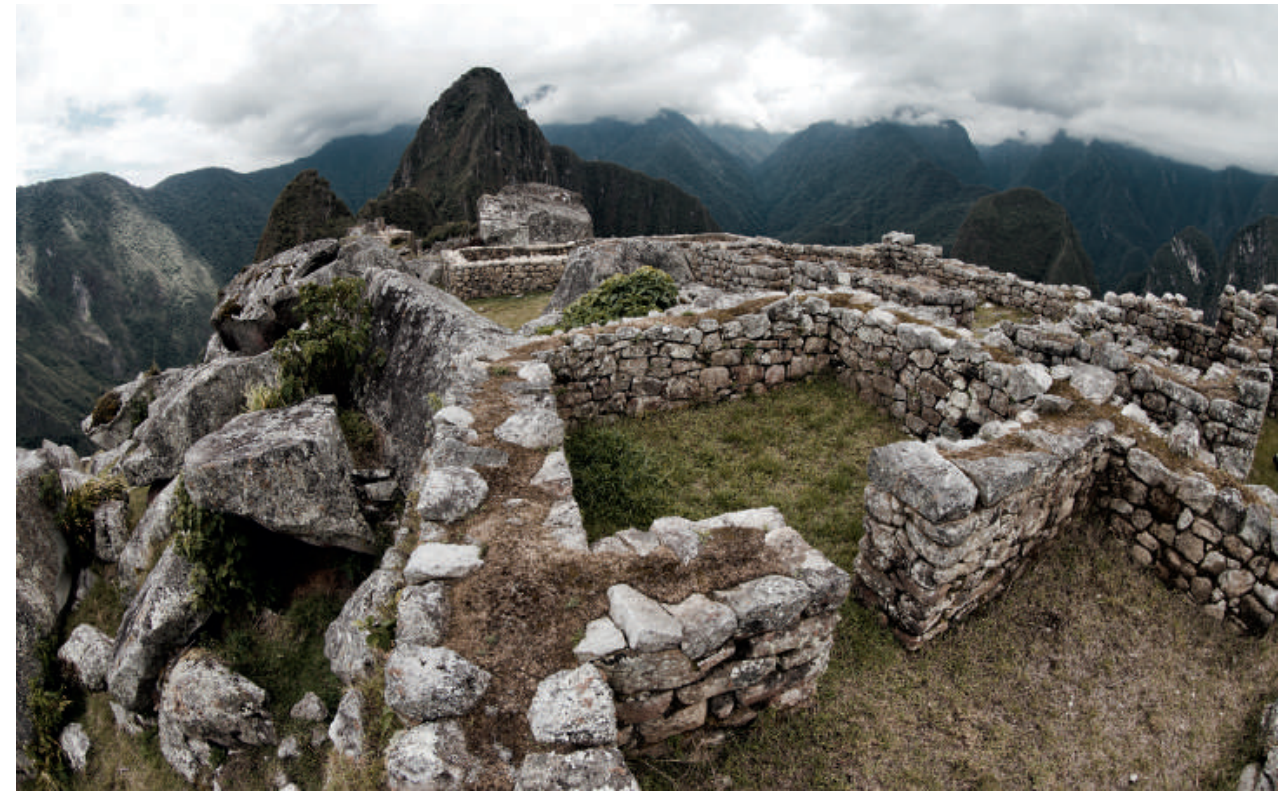

Figura 39. Recinto 31A. Fotografía José Bastante.

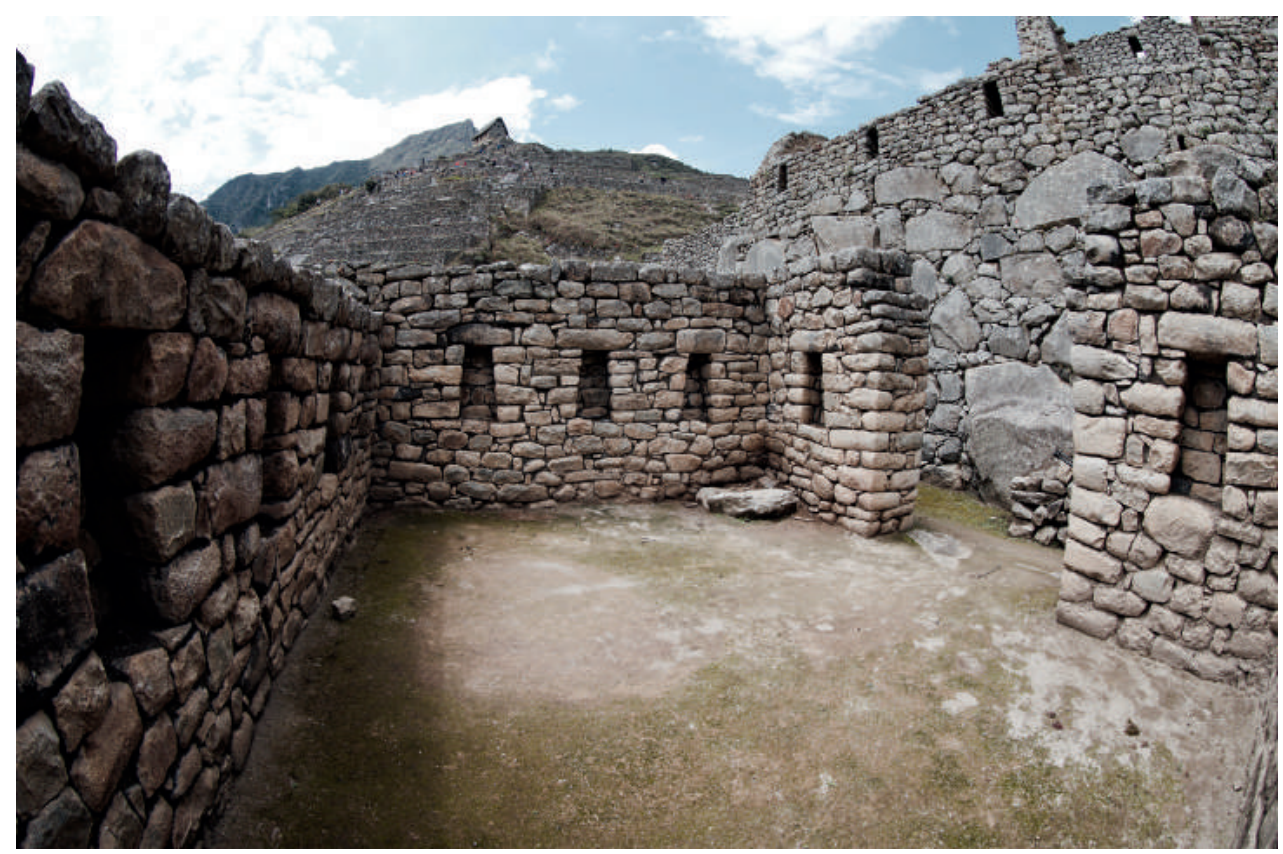

Figura 40. Recinto 72A. Fotografía José Bastante. 


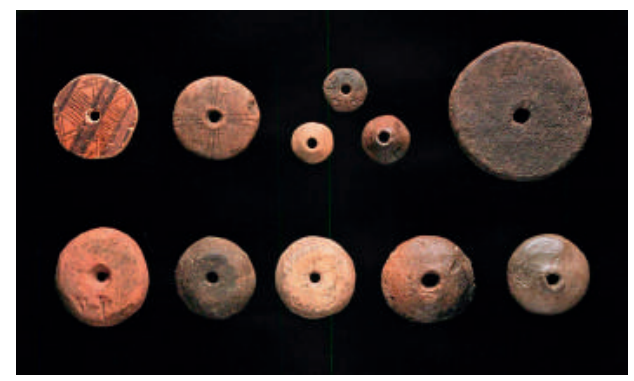

Figura 41. Fusayolas halladas durante la EPY de 1912 en la Llaqta de Machupicchu. Fotografía tomada de Salazar y Burger (2004).

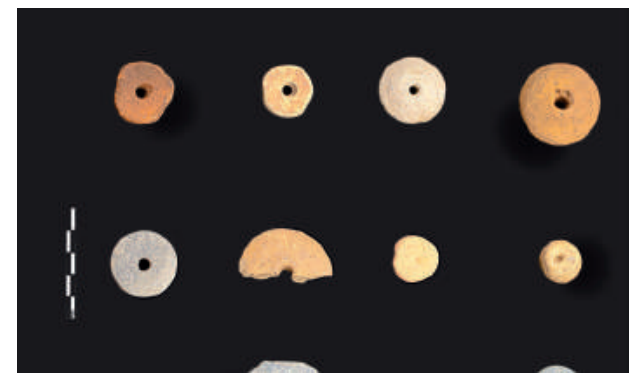

Figura 42. Fusayolas de cerámica y esquisto halladas durante la Temporada PIAISHM 2017 en la Llaqta de Machupicchu. Algunas en proceso de manufactura. Fotografía José Bastante.

Para el caso del Sector Espejos de Agua (Morteros - Fig. 45), con excepción de la excavación en el Recinto de los Espejos (47A - Fig. 46) donde solo se encontró fragmentos de cerámica y de un patio (46A - Fig. 47); la referencia de Bingham a que todos los otros recintos de este sector fueron excavados y no evidenciaron material (1930: 85) resulta cuestionable. Finalmente, a pesar de que Bingham manifiesta que se realizaron excavaciones entre la ventana de las sierpes y la fuente de agua No3 y en los recintos de Casa del Inka (1930: 95, 97), esta información no es del todo confiable.

El diario de Erdis también contiene información respecto a las recompensas por cierto tipo de descubrimientos (1912: 78) que no se limitaron a cráneos en posición original como refiere Bingham (1930: 14). De esta manera, los asistentes recibían por un esqueleto completo 80 centavos, por un cráneo 20 centavos, cráneo con mandíbula 30 centavos, por una vasija completa de 20 centavos a más, por un champe (objeto de metal) 20 centavos y por una roca marcada o tallada la recompensa era de 20 centavos (Erdis 1912: 32).

Para elaborar el reporte de las investigaciones de la EPY en la Llaqta de Machupicchu, Bingham se basó en gran medida en la información producida por Erdis e Eaton. Durante los cuatro meses que la EPY estuvo realizando trabajos en la Llaqta, el total de tiempo que Bingham permaneció en el sitio no fue mayor a un mes. Se dedicó a continuar con las exploraciones en la zona, principalmente en Vilcabamba, entusiasmado por las historias que escuchaba de distintos informantes sobre otras «ciudades perdidas». Ignacio Ferro le refirió la existencia del «Gran Machupicchu» en una montaña al sur de la Llaqta y Bingham no escatimó esfuerzos en ir a buscarla sin mayores resultados. Por su parte, Tomás Alvistur lo motivó a visitar «ruinas» como Llaqtapata, Palkay, Pampaqawana y Sapanmarka, entre otras (Bingham 1912). Durante la tercera y última EPY, Bingham fue informado de un sitio «mejor» que la Llaqta de Machupicchu, el cual estaba ubicado en el medio de un lago (1930: 23). 


\section{Estuco en la Llaqta de Machupicchu}

Una fotografía publicada por Bingham (Fig. 48) permite ver una gruesa capa de estuco de coloración rojiza al interior de un recinto (1913: 463, 471), el cual hemos logrado identificar en la kancha norte del Sector Tres Portadas (Fig. 43, 49 y 50). Asimismo, Bingham refiere que las paredes de algunos recintos presentaban evidencias de estucado (1912, 1930: 85), como es el caso del recinto ubicado en el extremo sureste de la Plaza de los Templos (Erdis 1912: 79) (Fig. 44).

$\mathrm{Si}$ a dichas evidencias agregamos los restos de pintura amarilla que Erdis encontraba permanentemente, la presencia de estuco definida en investigaciones posteriores e incluso la existencia actualmente (aunque en mínima cantidad) de este material en elementos líticos de algunas hornacinas del Sector Tres Portadas, ${ }^{9}$ resulta evidente que un gran porcentaje de los recintos de pirka en la Llaqta estuvieron estucados en el interior y en algunos casos en el exterior.

Por su parte, en el Sector Espejos de Agua (Fig. 45) se tiene un gran muro que marca su límite oeste y cuyos elementos líticos presentan una coloración rojiza. $\mathrm{Al}$ respecto, el estucado en este caso no fue externo. Sucede que los recintos en la

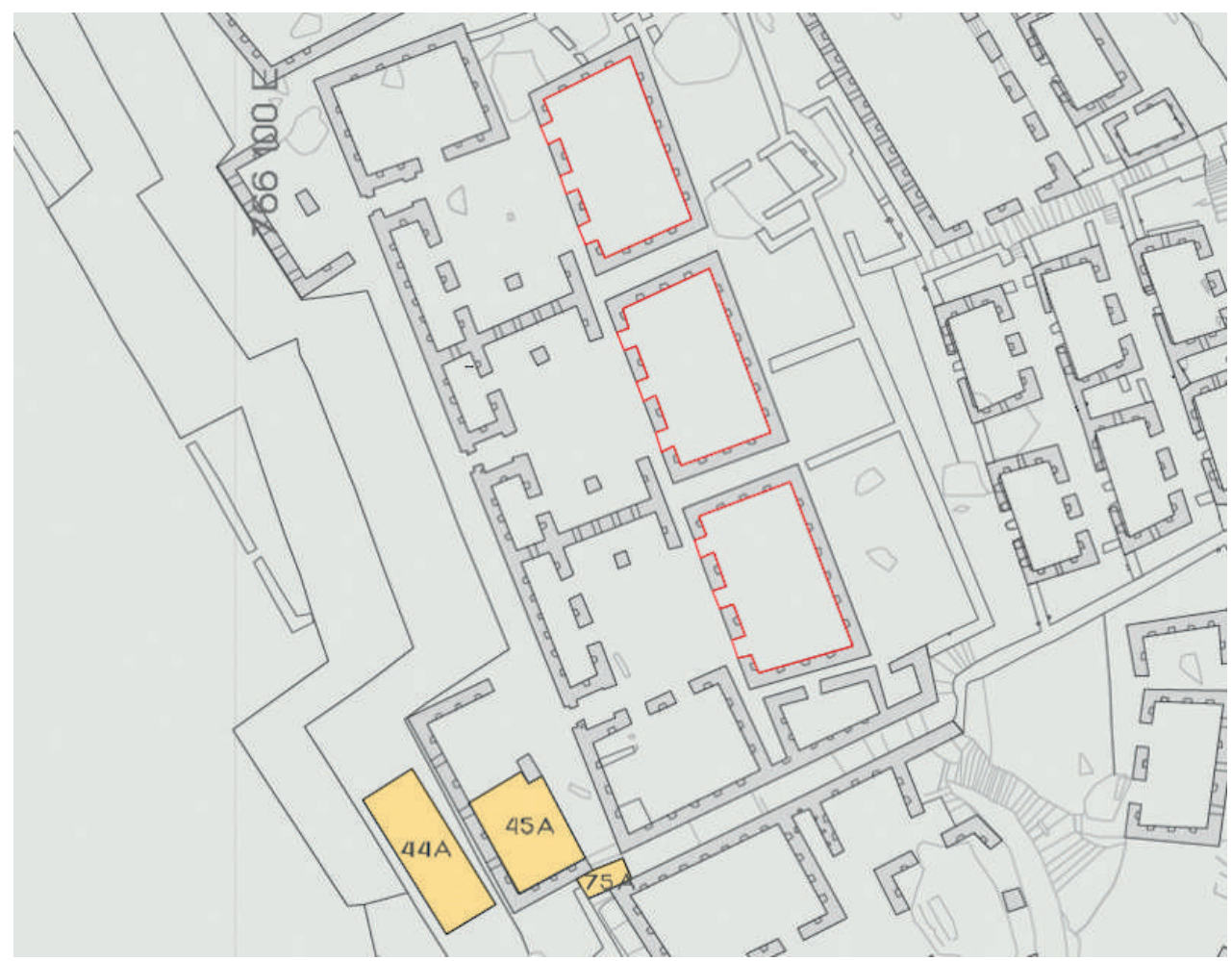

Figura 43. Excavaciones de 1912 en el Sector Tres Portadas. 


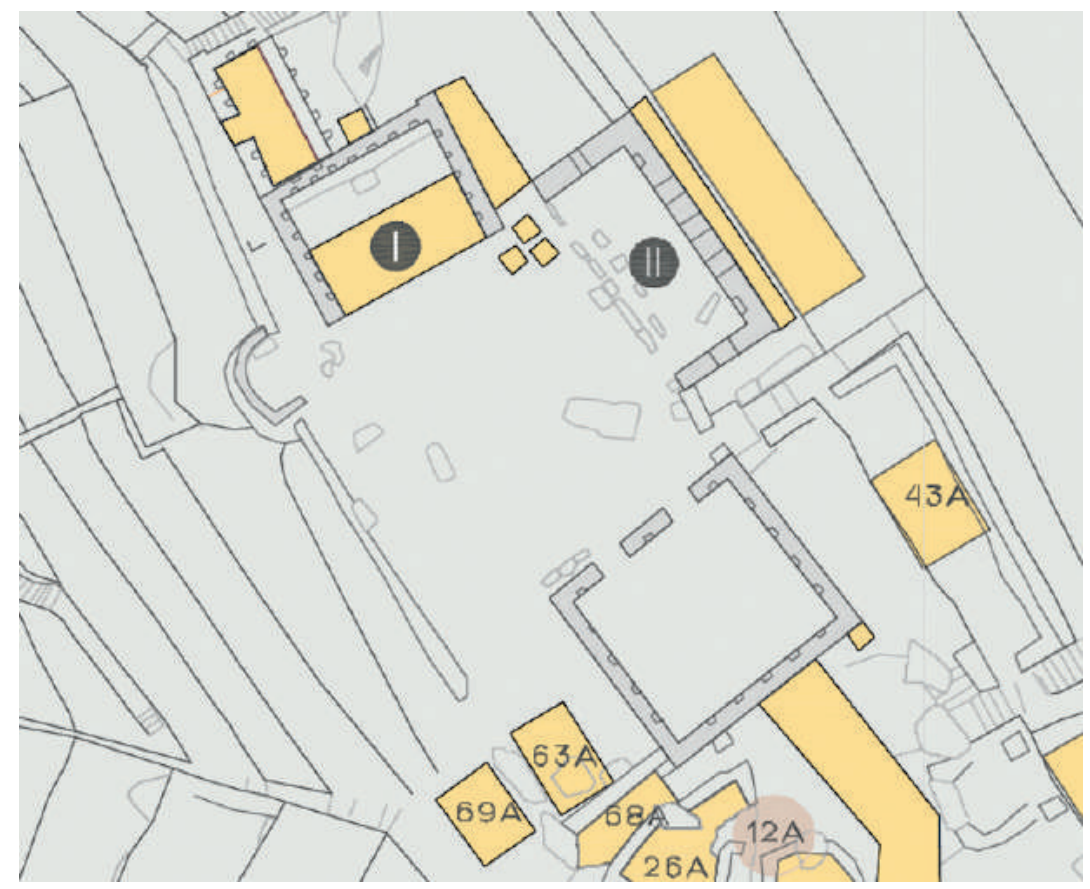

Figura 44. Excavaciones de 1912 en la Plaza de los Templos.

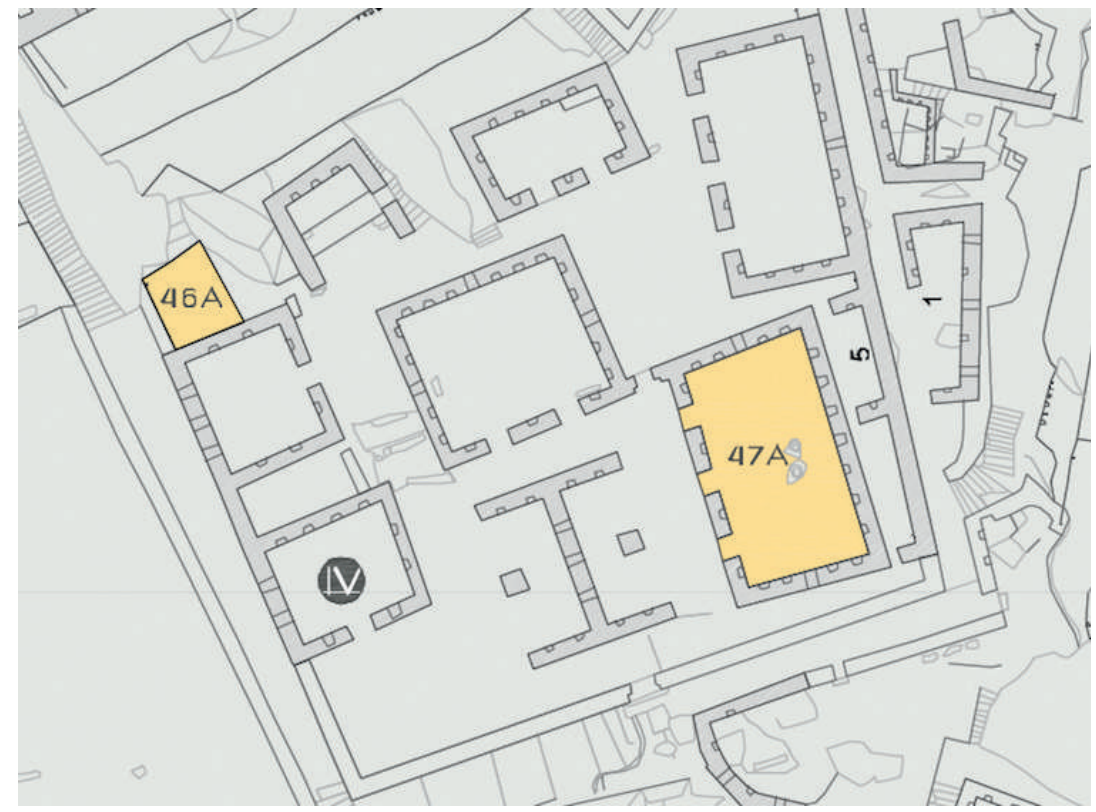

Figura 45. Excavaciones de 1912 en el Sector Espejos de Agua. 


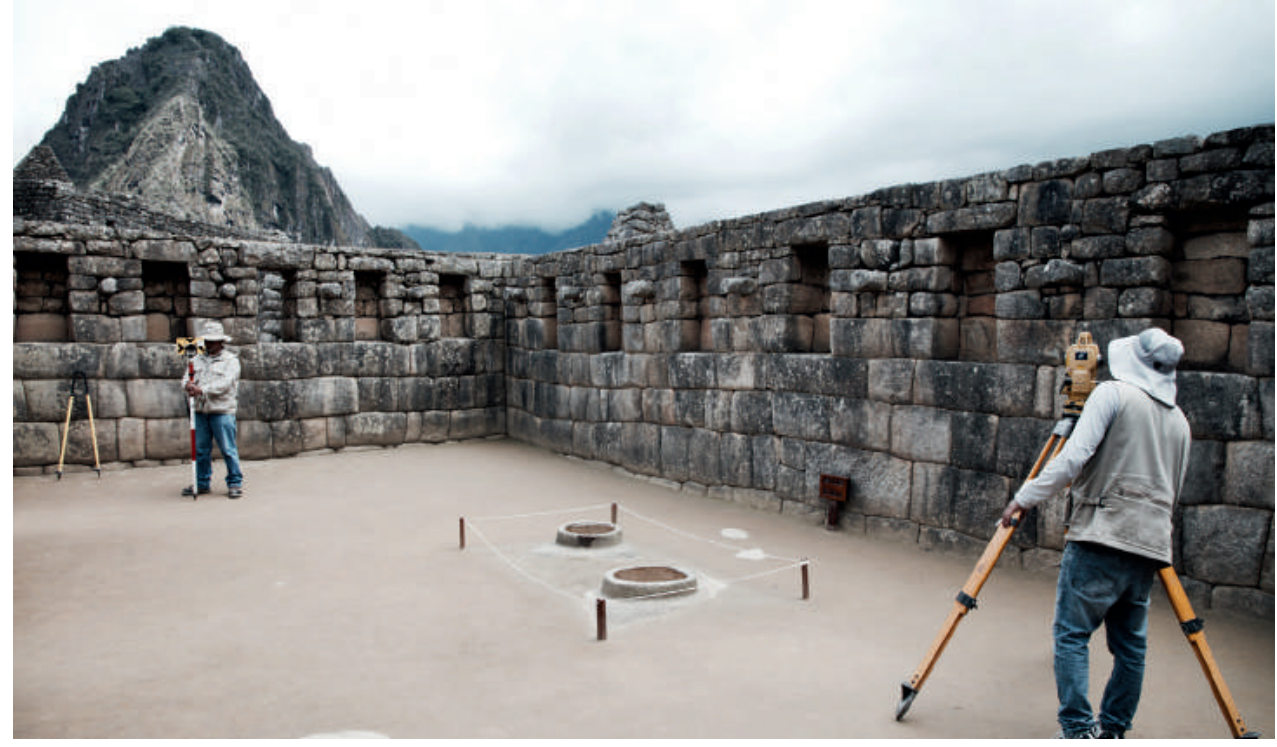

Figura 46. Recinto Espejos de Agua (47A). Fotografía José Bastante.

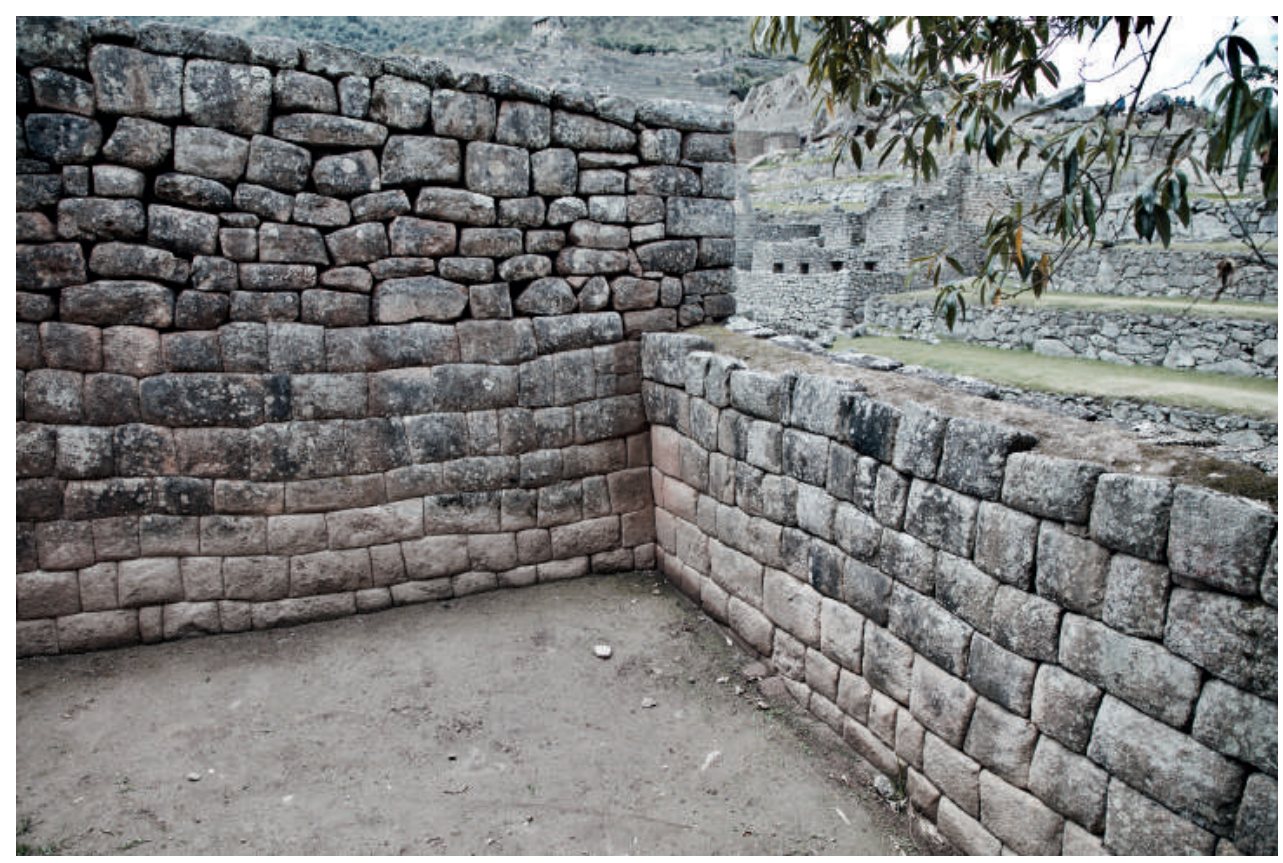

Figura 47. Patio en el Sector Espejos de Agua (46A). Fotografía José Bastante. 
parte superior, a pesar de presentar paramentos finos almohadillados, fueron estucados en el interior. Debido al abandono de la Llaqta y la subsecuente pérdida de los techos, las constantes precipitaciones pluviales de la zona desgastaron el estuco interno y la coloración rojiza se infiltró. Es por ello que la línea de elementos líticos con coloración rojiza que se aprecia en el muro externo coincide con el nivel de piso de los recintos superiores (Fig. 51).

\section{La supervisión por parte del Estado peruano y otros visitantes durante las excavaciones de 1912}

El encargado por el Gobierno peruano para supervisar los trabajos de la EPY de 1912 fue el profesor José Gabriel Cosio, quien solo realizó dos visitas durante el tiempo que permanecieron los integrantes de la EPY en el sitio (Erdis 1912: 59, $66,71)$. Cosio estaba presente cuando Richarte trajo algunos restos óseos, una olla y fragmentos de cerámica de la cueva 92 , todos en muy mal estado de conservación y con evidencias de haber sido expuestos al fuego (Erdis 1912: 62). Esta situación generó en Erdis algún tipo de satisfacción, ya que le incomodaba la presencia y preguntas de Cosio con respecto a los objetos que habían hallado. En su informe al Supremo Gobierno, Cosio menciona la existencia de un inventario de los objetos encontrados por la EPY en la Llaqta (1913: 31), el que no hemos podido ubicar hasta el momento.

Durante las excavaciones de la EPY en la Llaqta también arribaron otros personajes: el 23 de julio los Drs. Albert Giesecke, Rafael Aguilar y 13 estudiantes de la Universidad San Antonio Abad del Cusco visitaron el sitio (Erdis 1911:5) (Fig. 52), el mismo día que llegó Tomás Alvistur (Bingham 1912: 10). El 5 de agosto arribó el Ing. Monge quien comentó sobre «ruinas» a cuatro leguas sobre la colina y que el camino salía de Q’ente e iba por las montañas (Erdis 1912: 63). Mientras que el 30 de octubre, Erdis recibió la visita de los Sres. Arteta, Aranibar y de Alberto Duque. Este último se quedó para fotografiar el sitio (Erdis 1912: 72) pero sus registros se mantienen inubicables hasta el momento.

Cabe recordar que el dueño de la hacienda Sillque, Mariano Ignacio Ferro había instruido a los indígenas que habitaban la zona ${ }^{10}$ de apoyar a la EPY (Eaton 1916: 5; Bingham 1930: 14). Su hijo Ignacio llegó a la Llaqta con una cuadrilla de asistentes y apoyó a la EPY con trabajos de limpieza. También realizó excavaciones superficiales por su cuenta en algunos lugares como el Torreón donde no halló nada (Erdis 1912: 9).

\section{Consideraciones finales}

El análisis de los documentos de las EPY nos viene permitiendo lograr un mayor entendimiento respecto a los sucesos ocurridos en relación a la Llaqta de 


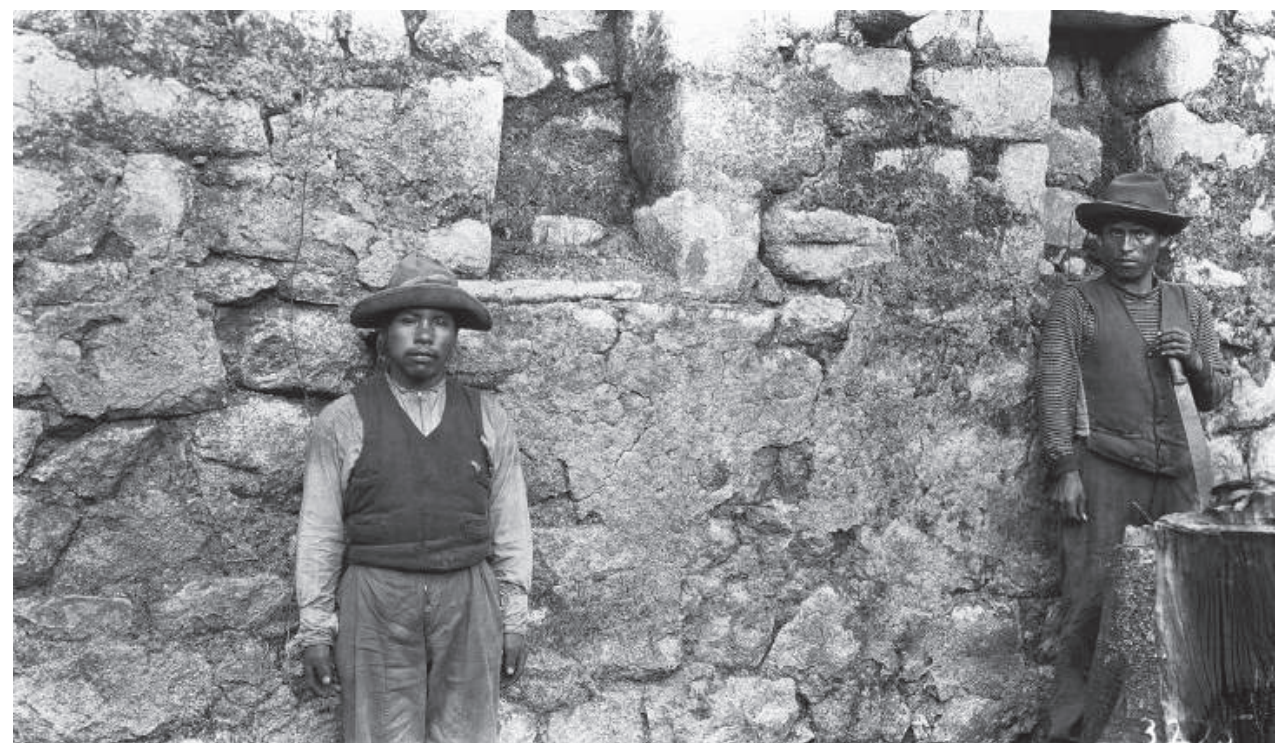

Figura 48. El recinto que registró la mayor cantidad de estuco. Fotografía Hiram Bingham (1912) Cortesía National Geographic Society.

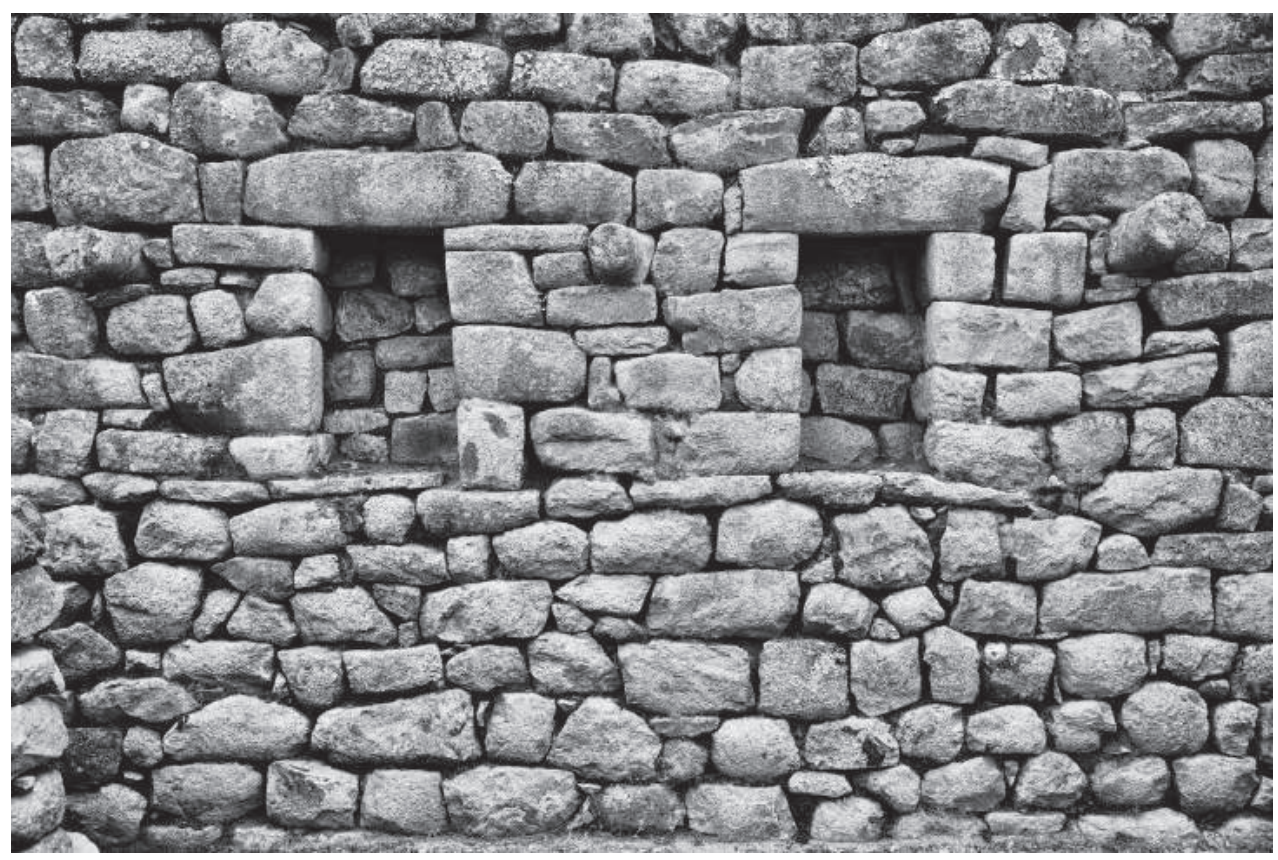

Figura 49. El muro de la figura 48 en la actualidad. Fotografía: José Bastante. 


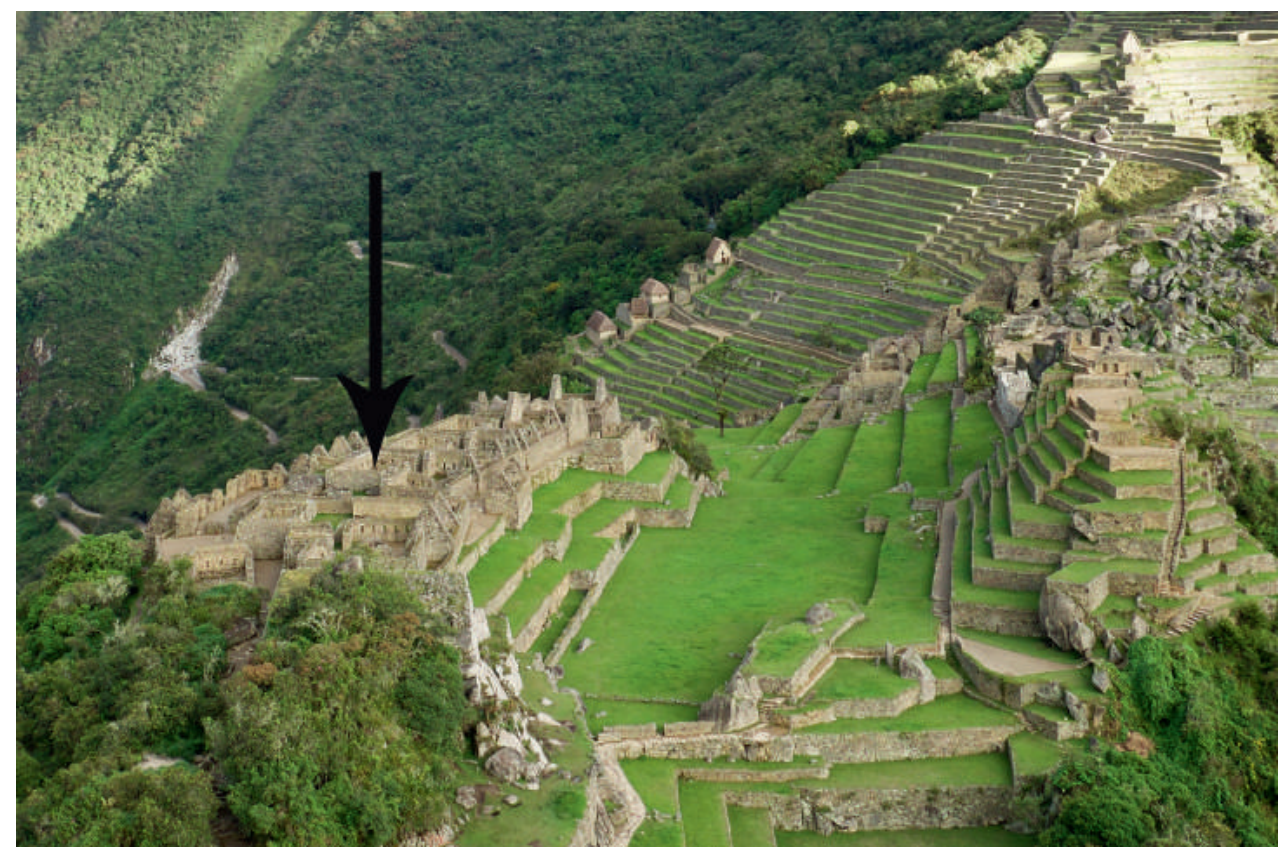

Figura 50. Ubicación del recinto que registró la mayor cantidad de estuco en sus paredes internas en el año 1912. Fotografía José Bastante.

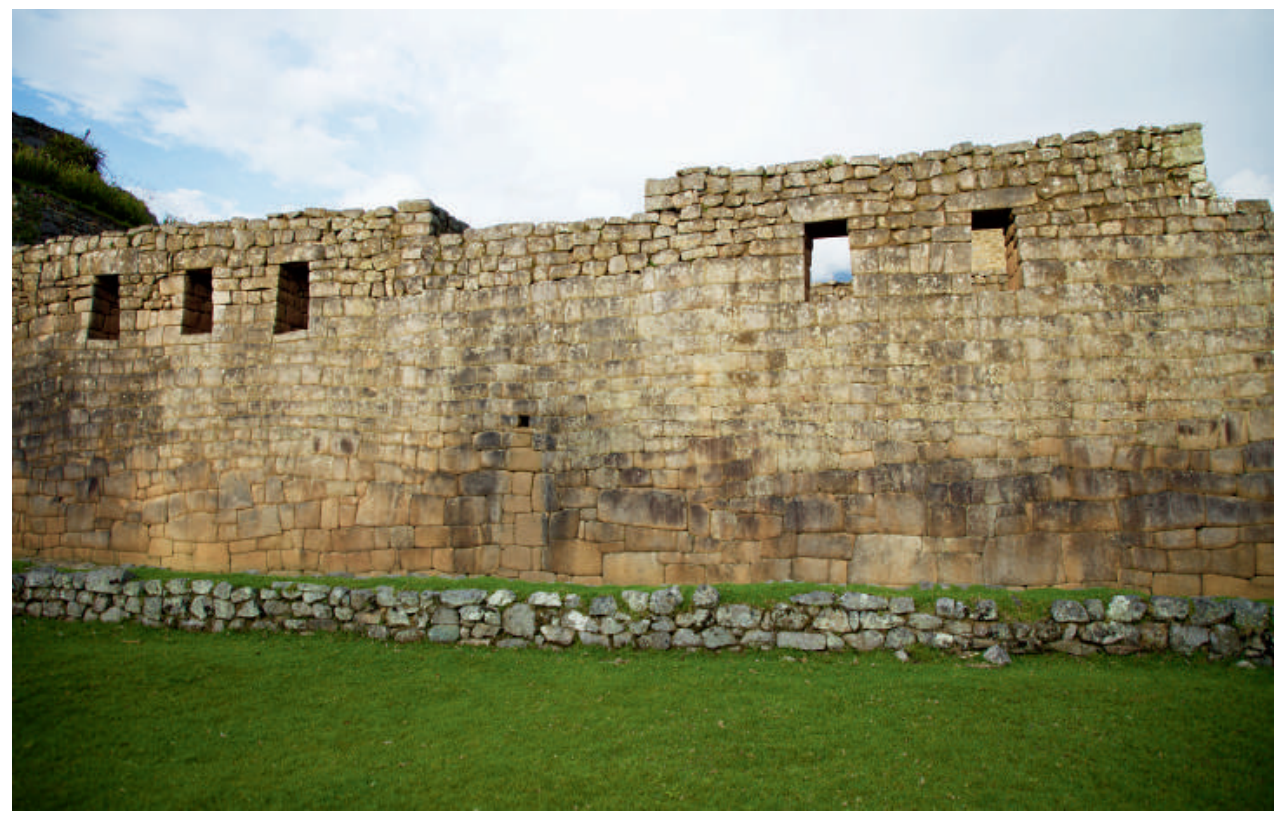

Figura 51. Los recintos de la parte superior estuvieron estucados con arcilla rojiza. Nótese la coloración del muro externo que coincide principalmente con el nivel del piso de los recintos superiores. Fotografía José Bastante. 
Machupicchu durante la segunda década del siglo XX. Las excavaciones ejecutadas por la EPY de 1912 y su contextualización (considerando las limitaciones descritas) con investigaciones posteriores nos brindan mayores luces respecto a las funciones que este monumento arqueológico y los que se encuentran dentro de su área de influencia directa cumplieron durante su relativamente corta vida activa.

Si bien las evidencias indican que la Llaqta y demás emplazamientos en la zona fueron expuestos a un saqueo prolongado a partir de su abandono durante el comienzo de la segunda mitad del siglo XVI; la interpretación del registro arqueológico e histórico ha permitido definir que el lugar fungió como un foco de interacción entre los dominios andino y amazónico, siendo un centro administrativo, político y religioso de suma importancia durante el Horizonte Tardío, cuya influencia y control abarcó los espacios de Picchu y Vilcabamba. Asimismo, es importante recalcar su evidente importancia religiosa y que la zona fue un escenario estratégico para el intercambio de productos entre grupos amazónicos y serranos desde periodos anteriores (Bastante y Fernández 2017).

Por otro lado, en mérito al Memorándum de Entendimiento suscrito en noviembre de 2010 entre la República del Perú y la Universidad de Yale, la mayor parte de los objetos excavados en la Llaqta de Machupicchu por la EPY de 1912 han sido repatriados y se encuentran en el Museo Machupicchu de la Casa Concha en la ciudad de Cusco. Sin embargo, dicho memorándum no consideró los objetos arqueológicos excavados por Bingham en 1909, 1911 y 1912 (como el caso de Yuraq Rumi), así como los que fueron adquiridos en el país y exportados ilegalmente a los

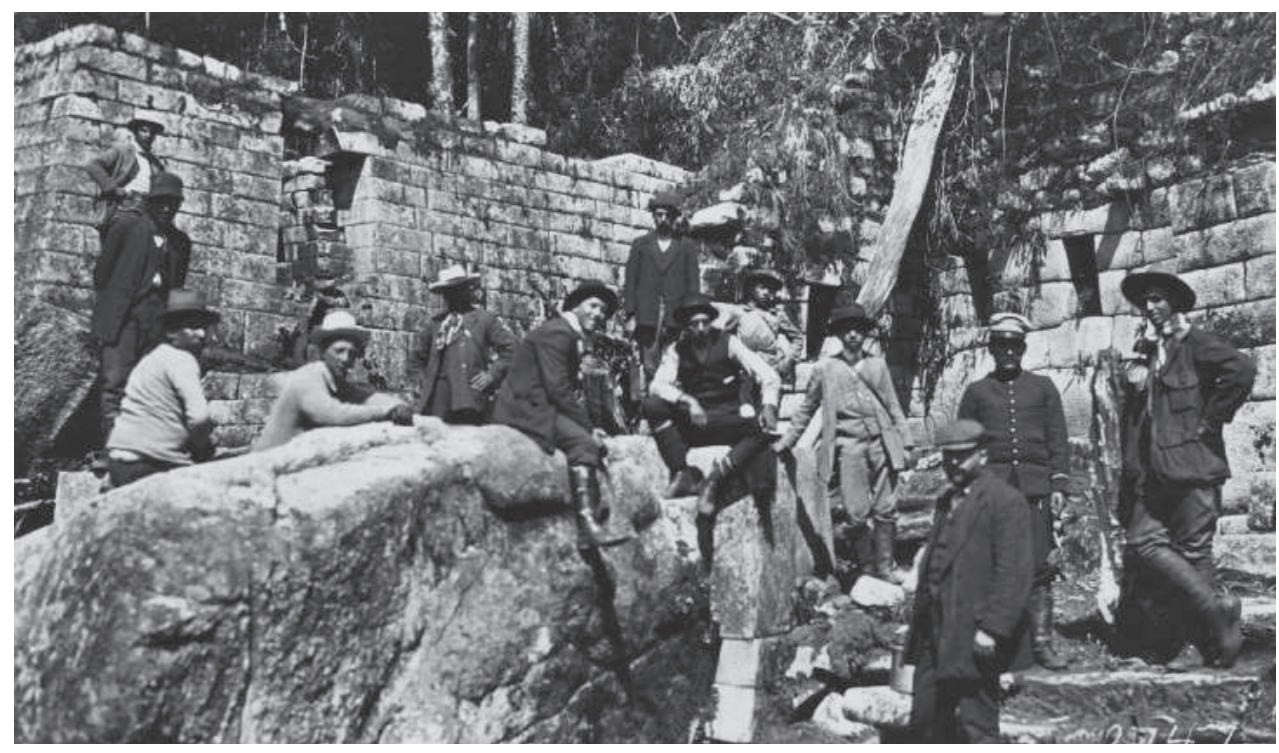

Figura 52. Visitantes de la Universidad San Antonio Abad del Cusco. Fotografía Ellwood Erdis (1912) - Cortesía National Geographic Society. 
EUA, en su mayoría piezas de museo; tampoco los informes, estudios, documentos y el abrumador registro fotográfico que las EPY lograron en el área andina. Este último constituye una fuente de información de suma importancia no solo con respecto a la Llaqta de Machupicchu sino a un sinnúmero de aspectos socio-culturales, arquitectónicos, históricos, biológicos, etc. del Perú y Bolivia.

Durante los últimos días en la Llaqta y luego de la limpieza final del sitio, Erdis ayudó a Bingham a tomar 500 fotografías (1930: 20). De las más de 11000 fotografías logradas por las EPY en el área andina (Bingham 1922: viii), probablemente un 10 por ciento corresponde a la Llaqta de Machupicchu. De éstas, el Parque Arqueológico Nacional de Machupicchu solo cuenta con 160, las que han sido entregadas por la National Geographic Society. En función a estas fotografías y a las imágenes comparativas logradas por el equipo del PIAISHM en 2014, se ha logrado evidenciar que si bien han habido restauraciones en la Llaqta de Machupicchu (principalmente durante las décadas de 1950 y 1960), ésta mantiene su originalidad y autenticidad, motivos por los cuales el SHM-PANM se encuentra inscrito en la Lista del Patrimonio Mundial de la UNESCO (Bastante 2016a: 274).

Finalmente, de acuerdo con la nómina de pagos de Erdis, es importante reconocer la labor de los peruanos que trabajaron con la EPY de 1912 realizando labores de limpieza/excavación en la Llaqta de Machupicchu y quienes en su mayoría, nunca han sido mencionados: Toribio Richarte, Anacleto Álvarez, Tomás Fuentes, José Espinoza, Isidro Rosas, Francisco Vallejo, Eusebio Moscoso, Jacinto Barrios, Justo Gonzales, José Dávalos, Pedro Reyes, Darío Galdo, Ponciano Loaiza, Antolín Ceballos, German Molina, Fermín Castañeda, Valentín Flores, Martín Huamán, Julián Andia, Feliciano Baca, Rosendo Uscamayca, Fabián Ore, Mariano Ore, Fidel Pinto, Eugenio Quispe, Gregorio Lima, Paulino Acurio, Leocadio Barrios, Blas Usca, Fabián Laura, Benedicto Paucar, Casimiro Mesa, Miguel Chalco, Máximo Chuiso, Eusebio Tiahualta, Juan Correa, Bernabé Acostupa, Pablo Sánchez, Pablo Quispe, Eusebio Quispe, Santiago Huamán, Fortunato Hilla, Gregorio González, Jacinto Hilla, Jacinto Quillahuamán, Pascual Mesa, Eugenio Tiahualpa, José Quispe, Pascual Usca, Enrique Flores, Avelino Lizárraga, Enrique Lizárraga, Basilio Carasas, Eugenio Tiahualpa, Gregorio Tapia, Luis Pilco, Francisco Cuba, Jacinto Huamán, Samuel Olivera, Andrés Lizarazo, César Ochoa, Eusebio Segura, Dionisio Pilco, Lucio Pilco, Matías Cobos, Francisco Cobos, Lorenzo Sorumiarles, Salome Huiñapu, Luis Mendizábal, Julián Canal, Miguel Olayunca, Simón Cárdenas, Manuel Vera, Nicomedes Mosquera, Avelino Pareja, Crespín Perón, Santos Ceballos, Ángel Pareja, Mariano Álvarez, Zaragoza Domínguez, Epifanio Tapia, Samuel Bujanda, Pablo Lobón, Samuel Nuñez, Fortunato Olayunca, Félix Berrio, Julián Berrio, Isidro Alegría, Enrique Morante, Andrés Cárdenas. 


\section{Agradecimientos}

Fernando Astete, Mariusz Ziółkowski, Richard Burger, Lucy Salazar, National Geographic Society, Dominika Sieczkowska, Josh Erickson, Edwin Cobos y Janelly Paucara.

\section{Notas}

1 Arrendire en Mandorpampa, a la altura del actual km 114.5 de la línea férrea Cusco - Hidroeléctrica.

2 La cual empleó no solo en su artículo de «Vitcos» (Bingham 1912) y en «Lost City of the Incas» (1948), sino también en «The Ruins of Espíritu Pampa» (Bingham 1914: 198), «Inca Land» (1922) y en «Citadel of the Incas» (1930).

3 Arrendire en Intiwatana, a 800 metros del puente San Miguel.

4 Hermano mayor de Ángel Lizárraga y arrendire en San Miguel.

$5 \quad$ Las traducciones de citas textuales al español son nuestras.

6 El registro de las cuevas No2 y No5 estuvo a cargo de Bingham.

7 En su diario de campo, Bingham (1912) menciona que con la ayuda de Erdis se numeraron todos los recintos, rocas y escalinatas en el mapa de Tucker de 1911. Por su parte, Erdis no hace referencia a ésto y dicho mapa no se encuentra entre los YPEP.

8 Los cálculos que hemos realizado en el grupo de Andenes Orientales indican que en menos de dos años, sin un mantenimiento permanente, el monumento se cubriría completamente por vegetación.

9 La presencia de estuco es visible actualmente en otros monumentos arqueológicos del SHMPAM como el caso de Chachabamba y Choqesuysuy.

10 A través del Sr. Jara, a quien Bingham se refiere como un espía (1912: 11).

\section{Referencias citadas}

Astete, Fernando, José Bastante y Gori Echevarría

2016 Quilcas en el Santuario Histórico de Machupicchu-Parque Arqueológico Nacional de Machupicchu: Análisis y perspectivas arqueológicas. Revista Haucaypata: 62-86.

Bastante, José

2016a Investigaciones Interdisciplinarias en la Llaqta de Machupicchu. Arqueología y Sociedad 32: 267-276.

2016b Informe Anual del Programa de Investigaciones Arqueológicas e Interdisciplinarias en el Santuario Histórico de Machupicchu. Parque Arqueológico Nacional de Machupicchu/Dirección Desconcentrada de Cultura Cusco/Ministerio de Cultura.

Bastante, José y Alicia Fernández

2018 Avances de las investigaciones interdisciplinarias en Machupicchu. $R e$ vista Haucaypata 13: 34-59 
Bestor, Paul

1912

Bestor's Journal 1912 Expedition. Yale Peruvian Expedition Papers. Collection MS 664. Series III, Box 19, Folder 14. Manuscripts and ArchiBingham, Hiram ves. Yale University Library.

1911a Bingham's Journal 1911 Expedition. Yale Peruvian Expedition Papers. Collection MS 664. Series III, Box 18, Folders 1 \& 2. Manuscripts and Archives. Yale University Library.

1911b Yale Peruvian Expedition Preliminary Account. Yale Peruvian Expedition Papers. Collection MS 664. Series III, Box 18, Folder 3. Manuscripts and Archives. Yale University Library.

1912 Bingham's Journal 1912 Expedition. Yale Peruvian Expedition Papers. Collection MS 664. Series III, Box 19, Folder 15. Manuscripts and Archives. Yale University Library.

1913 In the Wonderland of Peru. National Geographic 24: 387-573.

1922 Inca Land: Explorations in the Highlands of Peru. $2^{\text {nd }}$ edition. Houghton Mifflin, Boston.

1930 Machu Picchu, a Citadel of the Incas. Yale University Press, New Haven.

1948 Lost City of the Incas: The Story of Machu Picchu and Its Builders. Duell, Sloan and Pearce, New York.

Burger, Richard L.

2004 Scientific Insights into Daily Life at Machu Picchu. En Machu Picchu. Unveiling the Mystery of the Incas, editado por Richard L. Burger y Lucy

C. Salazar. Yale University Press, New Haven.

Burger, Richard L. y Lucy C. Salazar (editores)

2012 The 1912 Yale Peruvian Scientific Expedition Collections from Machu Picchu: Metal Artifacts. Yale University Publications in Anthropology 91, New Haven.

Cosio, José Gabriel

1912a Una Excursión a Machupicchu, ciudad antigua. Revista Universitaria de la UNSAAC 2, Año I, Septiembre. Cusco.

1912b Una Excursión a Machupicchu, ciudad antigua. Revista Universitaria de la UNSAAC 3, Año I, Diciembre. Cusco.

1913 Informe elevado al Ministerio de Instrucción por el Dr. José Gabriel Cosio, Delegado del Supremo Gobierno y de la Sociedad Geográfica de Lima, ante la Comisión Científica de 1912 enviada por la Universidad de Yale, acerca de los trabajos realizados por ella en el Cuzco y Apurímac. Revista Universitaria de la UNSAAC 5, Año II, Junio. Cusco. 
Eaton, George

1916 The Collection of Osteological Material from Machu Picchu. Memoirs of the Connecticut Academy of Arts and Sciences 5. Yale University Press, New Haven.

1916 [1990] La Colección del Material Osteológico de Machu Picchu. [traducción y Erdis, Ellwood prólogo de Sonia Guillén]. Rumi Maqui Editores, Lima.

1912 Erdis's Journal 1912 Expedition. Yale Peruvian Expedition Papers. Collection MS 664. Series III, Box 19, Folders 19 \& 20. Manuscripts and Archives. Yale University Library.

Gentile, Margarita

1998 La pichca: oráculo y juego de fortuna (su persistencia en el espacio y tiempo andinos). Bulletin de l'Institut français d'études andines 27: 75131

Gordon, Robert

2012 Metal Artifacts from the 1911-1912 Yale Peruvian Expeditions to Peru. En The 1912 Yale Peruvian Scientific Expedition Collections from $\mathrm{Ma}$ chu Picchu: Metal Artifacts, editado por Richard L. Burger y Lucy C. Salazar, pp. 1-72. Yale University Publications in Anthropology 91, New Haven

Gordon, Robert B. y John W. Rutledge

1984 Bismuth Bronze from Machu Picchu, Peru. Science 223 (4636): 585586.

Lanius, Paul

1911

Lanius's Journal 1911 Expedition. Yale Peruvian Expedition Papers. Collection MS 664. Series III, Box 18, Folders 9 \& 10. Manuscripts and Archives. Yale University Library.

Mathewson, Champion H.

1915 A Metallographic Description of Some Ancient Peruvian Bronzes from Machu Picchu. American Journal of Science 240: 525-616.

Miller, George

2003 Food for the Dead, Tools for the Afterlife: Zooarchaeology at Machu Picchu. En The 1912 Yale Peruvian Scientific Expedition Collections from Machu Picchu: Human and Animal Remains, editado por Richard L. Burger y Lucy C. Salazar, pp. 119-137. Yale University Publications in Anthropology 85, New Haven.

Owen, Bruce

2012 The Meanings of Metals: The Inca and Regional Contexts of Quotidian Metals from Machu Picchu. En The 1912 Yale Peruvian Scientific Expedition Collections from Machu Picchu: Metal Artifacts, editado por 
Reinhard, Johan

Richard L. Burger y Lucy C. Salazar, pp. 73-189. Yale University Publications in Anthropology 91, New Haven

1991 [2002] Machu Picchu, El Centro Sagrado. Instituto Machu Picchu/Editora Automas S.A., Cusco.

2007 Machu Picchu. Exploring an Ancient Sacred Center. Cotsen Institute of Archaeology/University of California, Los Angeles.

Rowe, John H.

1946 IInca Culture at the Time of the Spanish Conquest. En Handbook of South American Indians, vol. 2, editado por Julian H. Steward, pp. 183330. Smithsonian Institution, Washington.

1990 Machu Picchu a la Luz de Documentos de Siglo XVI. Histórica 14(1): 139-154.

Salazar, Lucy

2007 Machu Picchu's silent majority: A consideration of the Inka cemeteries. En Variations in the Expression of Inka Power, editado por Richard L. Burger, Craig Morris y Ramiro Matos Mendieta, pp. 165-184. Dumbarton Oaks Research Library, Washington DC.

Salazar, Lucy y Richard Burger

2004 Catalogue. En Machu Picchu. Unveiling the Mystery of the Incas, editado por Richard L. Burger y Lucy C. Salazar. Yale University Press, New Haven. 